\title{
Article \\ Optimal Incorporation of Photovoltaic Energy and Battery Energy Storage Systems in Distribution Networks Considering Uncertainties of Demand and Generation
}

\author{
Hussein Abdel-Mawgoud ${ }^{1}\left(\mathbb{D}\right.$, Salah Kamel ${ }^{1} \mathbb{D}$, Marcos Tostado-Véliz ${ }^{2, * \mathbb{D}}$, Ehab E. Elattar ${ }^{3, * \mathbb{D}}$ \\ and Mahmoud M. Hussein ${ }^{1,4}(\mathbb{D}$
}

check for

updates

Citation: Abdel-Mawgoud, H.; Kamel, S.; Tostado-Véliz, M.; Elattar, E.E.; Hussein, M.M. Optimal Incorporation of Photovoltaic Energy and Battery Energy Storage Systems in Distribution Networks Considering Uncertainties of Demand and Generation. Appl. Sci. 2021, 11, 8231. https://doi.org/10.3390/ app11178231

Academic Editor: Fabio La Foresta

Received: 1 July 2021

Accepted: 1 September 2021

Published: 5 September 2021

Publisher's Note: MDPI stays neutral with regard to jurisdictional claims in published maps and institutional affiliations.

Copyright: (c) 2021 by the authors. Licensee MDPI, Basel, Switzerland. This article is an open access article distributed under the terms and conditions of the Creative Commons Attribution (CC BY) license (https:/ / creativecommons.org/licenses/by/ $4.0 /)$.
1 Department of Electrical Engineering, Faculty of Engineering, Aswan University, Aswan 81542, Egypt; hussein.abdelmawgoud@yahoo.com (H.A.-M.); skamel@aswu.edu.eg (S.K.); mahmoud_hussein@aswu.edu.eg (M.M.H.)

2 Electrical Engineering Department, University of Jaen, EPS, 23700 Linares, Spain

3 Department of Electrical Engineering, College of Engineering, Taif University, P.O. Box 11099, Taif 21944, Saudi Arabia

4 Department of Electrical Engineering, Faculty of Energy Engineering, Aswan University, Aswan 81528, Egypt

* Correspondence: mtostado@ujaen.es (M.T.-V.); e.elattar@tu.edu.sa (E.E.E.)

\begin{abstract}
In this paper, the Archimedes optimization algorithm (AOA) is applied as a recent metaheuristic optimization algorithm to reduce energy losses and capture the size of incorporating a battery energy storage system (BESS) and photovoltaics (PV) within a distribution system. AOA is designed with revelation from Archimedes' principle, an impressive physics law. AOA mimics the attitude of buoyant force applied upward on an object, partially or entirely dipped in liquid, which is relative to the weight of the dislodged liquid. Furthermore, the developed algorithm is evolved for sizing several PVs and BESSs considering the changing demand over time and the probability generation. The studied IEEE 69-bus distribution network system has different types of the load, such as residential, industrial, and commercial loads. The simulation results indicate the robustness of the proposed algorithm for computing the best size of multiple PVs and BESSs with a significant reduction in the power system losses. Additionally, the AOA algorithm has an efficient balancing between the exploration and exploitation phases to avoid the local solutions and go to the best global solutions, compared with other studied algorithms.
\end{abstract}

Keywords: photovoltaics; BESS; optimization; AOA algorithm; uncertainty; distribution network

\section{Introduction}

Recently, the penetration of PV systems into the electric grid has been increased in most countries to take advantage of the environment as well as the economic benefits. PV energy systems do not emit polluting gases such as traditional energy sources, and the owners of PV energy systems obtain incentives from utilities by selling the output energy from their PV units at a high price [1-3]. PV output is variable during the day as it depends on the variable natural source $[4,5]$. The designing, optimization, and planning of PV has been presented in [6-8]. The allocation of the PV energy system near the loads in the distribution system leads to improvement in voltage profile and to a decrease the emission, cost, and system losses as in $[9,10]$. The optimal planning of PV in a realistic case has been presented in [11]. In [12,13], an analytical method has been applied to decrease the system loss by incorporating PV in distribution networks. In [14], the optimal allocation of electric vehicles with a combination of PV and battery storage to reduce the total system cost is presented. Additionally, the optimal planning of PV with electric vehicles in distribution networks to decrease the system loss is presented in [15]. Incorporating PV in the distribution system to decrease the system loss and to improve the bus system voltage is introduced in $[16,17]$. Nevertheless, the high penetration of the PV energy system with the variation 
in demand exposes the distribution systems to various problems, such as fluctuations of power, voltage rise, extraordinary energy losses, and a low stability of voltage $[1,18,19]$. Therefore, load curtailment and integration of energy storage systems has been exploited to decrease power fluctuations and overcome any system constraint violations [1].

Nowadays, the integration of DG into distribution systems considering the energy losses has enticed attention. Research on the allocation of renewable DG (e.g., solar, wind and biomass) has been proposed to reduce energy loss, considering the variations of power generation and load demand $[11,14,15]$. According to the presence load type characteristics, optimum DG power factor dispatch for every load level would be an integral part for reducing energy losses. Nevertheless, most of the current research assumed that the DG systems work at predefined power factors.

In contrast to generation systems that depend on conventional generation techniques such as gas turbines and reciprocating engines, PV energy resources are non-dispatchable and intermittent, depending on temperature and radiation. The BESS technologies create a chance to transform the PV energy resources from non-dispatchable systems to dispatchable systems with similar conventional resources [20,21]. Throughout the past two decades, a hybrid system of BESS and PV has been considered for the applications of stand-alone systems [22-24]. Recently, the hybrid system of PV and BESS has been exploited as one of the furthermost worthwhile solutions in grid-connected applications to increase the penetration of the PV energy system in distribution systems. Such hybrid design helps alleviate the influences of intermittency in the PV energy systems, and offers many benefits for the owners of PV system, customers, and utilities. Many researchers have devoted their efforts to this interesting topic [18-20,25-31]. A hybrid PV-BESS has been evolved for applications of load demand-side to improve the efficiency of the electrical system [25,26]. In [27], authors have proposed an optimal BESS charging and discharging schedule in a PV grid-connected system for shaving of peak demand. Authors in [28] have presented a methodology to calculate the BESS size for shaving of peak load and power balance used in case of connecting PV energy system with the grid. In [29], authors have presented a methodology to compute the BESS size for raising the penetration of the PV energy system in case of residential system load with the objectives of voltage regulation and decreasing in maximum output power and yearly cost. A discharging and charging strategy for the BESS has been suggested to alleviate abrupt changes in the output power of the PV energy system and boost the evening peak load in the case of a residential load system [30]. The authors in [18] have proposed a conception of voltage regulation voltages in the distribution systems with high penetration of PV energy system by adjusting the output power of BESS at customer-side. BESS has been controlled and sized to diminish the fluctuation in the PV output power [20,31]. In [19], the authors have evolved the BESS's best discharging and charging schedule on an hourly basis to alleviate the discontinuity of PV output by reducing the energy loss.

Generally, the previous review indicates that significant research has been published on the size and discharging and discharging schedules of the BESS exploited in the case of connecting the PV energy system with the grid. Nevertheless, most of the research introduced has supposed that the optimal power factor dispatch for every hybrid PV-BESS throughout all of the time intervals is ignored as well and the size of PV units exploited in hybrid PV-BESS is prespecified. Based on the characteristics of the loads served, every PV-BESS hybrid that can provide reactive and active power with the optimum power factor may positively reduce energy losses in distribution systems.

This paper shows a conception of involving a hybrid PV and BESS in residential, industrial, and commercial distribution systems, taking into account the system energy loss. Where the PV energy system is deemed as a non-dispatchable energy source as its power output cannot be controlled, BESS is considered as a dispatchable energy source as its power output can be controlled. In this paper, AOA is applied to reduce the energy losses and capture the size of incorporating a PV energy system and BESS in a distribution network. However, the paper contributions can be summarized as follows: 
- A new application of the Archimedes optimization algorithm for minimizing the energy losses and capture the size of incorporating battery energy storage system and photovoltaics in a distribution system.

- The developed algorithm is evolved for sizing several PVs and BESSs considering the changing demand over time and the probability generation.

- Validating the developed algorithm using IEEE 69-bus distribution network system which has different types of the load, such as residential, industrial, and commercial loads.

- The simulation results indicate the robustness of the proposed algorithm for computing the best size of multiple PVs and BESSs, with a significant reduction in the power system losses.

The remainder of this paper is constructed as following: the load, BESS, and PV modeling are introduced in Section 2. Also the problem formulation of BESS with PV is introduced in Section 2. The methodology of the proposed Archimedes optimization algorithm (AOA) has been presented in Section 3. The cases study on a 69-bus industrial, commercial, and residential distribution have been presented and discussed in Section 4. Section 5 offers the conclusions of the paper.

\section{Problem Formulation}

The two buses of the main feeder in the distribution network with a combination of PV and BES can be represented in Figure 1.

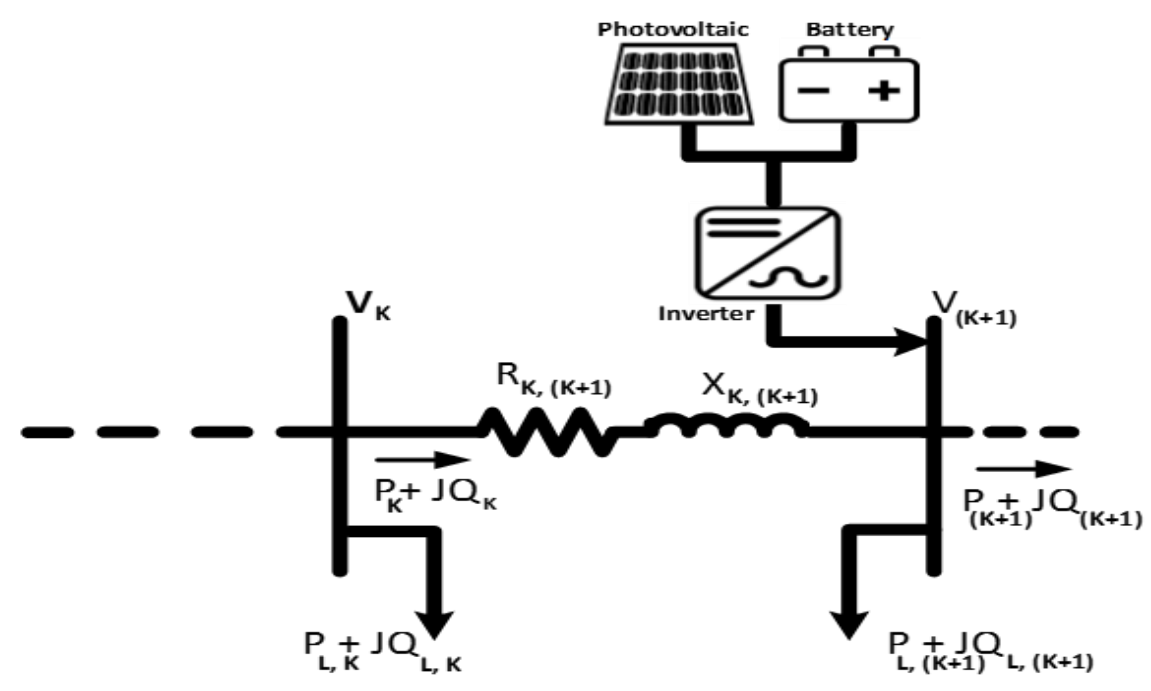

Figure 1. Two buses of radial distribution network.

Forward/backward sweep algorithm is utilized to obtain the system load flows. The reactive and real power flows are calculated by Equations (1) and (2), respectively [32].

$$
\begin{gathered}
P_{K}=P_{(K+1)}+P_{L,(K+1)}+R_{K,(K+1)}\left(\frac{\left(P_{(K+1)}+P_{L,(K+1)}\right)^{2}+\left(Q_{(K+1)}+Q_{L,(K+1)}\right)^{2}}{\left|V_{(K+1)}\right|^{2}}\right) \\
Q_{K}=Q_{(K+1)}+Q_{L,(K+1)}+X_{K,(K+1)}\left(\frac{\left(P_{(K+1)}+P_{L,(K+1)}\right)^{2}+\left(Q_{(K+1)}+Q_{L,(K+1)}\right)^{2}}{\left|V_{(K+1)}\right|^{2}}\right)
\end{gathered}
$$

where, $P_{(K+1)}$ and $Q_{(K+1)}$ represent the real and reactive power flow from bus $(K)$ to the next bus system, respectively. The reactive and real load flows between $(K)$ and $(K+1)$ buses are $Q_{K}$ and $P_{K}$, respectively. the reactance and resistance between $(K)$ and $(K+1)$ buses are $X_{K,(K+1)}$ and $R_{K,(K+1)}$, respectively. The reactive and real load at bus $(K+1)$ are $Q_{L,(K+1)}$ and $P_{L,(K+1)}$, respectively. 
The voltage magnitude of system buses is evaluated by Equation (3).

$$
V_{(K+1)}{ }^{2}=V_{K}^{2}-2\left(P_{K} R_{K,(K+1)}+Q_{K} X_{K,(K+1)}\right)+\left(R_{K,(K+1)}{ }^{2}+X_{K,(K+1)^{2}}\right)^{\left(P_{K}^{2}+Q_{K}^{2}\right)} \frac{V_{K}^{2}}{3}
$$

where $V_{(K+1)}$ and $V_{(K)}$ are the system voltage at buses $(K+1)$ and $(K)$, respectively. Installation of PV and BESS in RDS changes the load flows through the system branches. Therefore, Equations (1) and (2) are modified to Equations (4) and (5), respectively.

$$
\begin{gathered}
P_{K}=P_{(K+1)}+P_{L,(K+1)}+R_{K,(K+1)}\left(\frac{\left(P_{(K+1)}+P_{L,(K+1)}\right)^{2}+\left(Q_{(K+1)}+Q_{L,(K+1)}\right)^{2}}{\left|V_{(K+1)}\right|^{2}}\right)-P_{(P V+B E S S),(K+1)} \\
Q_{K}=Q_{(K+1)}+Q_{L,(K+1)}+X_{K,(K+1)}\left(\frac{\left(P_{(K+1)}+P_{L,(K+1)}\right)^{2}+\left(Q_{(K+1)}+Q_{L,(K+1)}\right)^{2}}{\left|V_{(K+1)}\right|^{2}}\right)-Q_{(P V+B E S S),(K+1)}
\end{gathered}
$$

where, $Q_{(P V+B E S),(K+1)}$ and $P_{(P V+B E S),(K+1)}$ are the injection reactive and real power from BESS and PV units at bus $(\boldsymbol{K}+\mathbf{1})$, respectively.

The ratio of system losses with incorporating BESS and PV to the system losses without incorporating BESS and PV in RDS is formulated as single objective function as shown in Equation (6).

$$
F_{o}=\sum\left(\frac{\sum_{h=1}^{24} P_{\text {loss }}(h)^{\text {after }(P V+B E S S)} \Delta(h)}{\sum_{h=1}^{24} P_{\text {loss }}(h)^{\text {before }(P V+B E S S)} \Delta(h)}\right), \quad h=1,2,3,4, \ldots \ldots . .24 h
$$

where, $\boldsymbol{P}_{\text {loss }}(t)^{\text {before }(P V+B E S)}$ and $\boldsymbol{P}_{\text {loss }}(\boldsymbol{h})^{\text {after }}(P V+B E S S)$ are the system losses before and after incorporating BESS and PV in distribution system at time $(\boldsymbol{h})$.

The inequality and equality constraints are formulated as shown next [33-36]:

\subsection{Equality Constraints}

These constraints include power flow balance equations. Therefore, the power generation from substation and PV with BESS should be equal to the system loss and system load demand as shown next.

$$
\begin{aligned}
P_{r f}+\sum_{g=1}^{G} P_{P V+B E S}(g) & =\sum_{j=1}^{m} \boldsymbol{P}_{L, j}+\sum_{n b=1}^{N B} \boldsymbol{P}_{l o s s}(n b) \\
Q_{r f}+\sum_{g=1}^{G} Q_{P V+B E S}(g) & =\sum_{j=1}^{m} Q_{L, j}+\sum_{n b=1}^{N B} Q_{l o s s}(n b)
\end{aligned}
$$

where $N B$ and $\mathrm{m}$ are the overall number of branches and buses, respectively. $Q_{\text {loss }}(n b)$ and $P_{l o s s}(n b)$ are the reactive and real system loss at branch $(j)$, respectively. $G$ are the overall number of PV with BESS. $\boldsymbol{Q}_{r f}$ and $\boldsymbol{P}_{r f}$ represents the reactive and active power drawn from substation in RDS, respectively.

\subsection{Inequality Constraints}

These constraints include system operating constraints such as system voltage limits, PV generation with BESS limits and branch current limits as follows:

\subsubsection{Voltage Limits}

The operating bus voltage should be between high $\left(V_{u p}\right)$ and low $\left(V_{l o}\right)$ voltage limits as shown in Equation (9).

$$
V_{l o} \leq V_{j} \leq V_{u p}
$$

where, $V_{j}$ represent the voltage at bus $j$. 
2.2.2. Sizing Limits of (PV + BESS)

$$
\begin{aligned}
\sum_{g=1}^{G} P_{P V+B E S}(g) \leq & \left(\sum_{j=1}^{m} P_{L, j}+\sum_{n b=1}^{N B} P_{l o s s}(n b)\right) \\
\sum_{m=1}^{G} Q_{P V-B E S}(m) \leq & \left(\sum_{j=1}^{m} Q_{L, j}+\sum_{n b=1}^{N B} Q_{l o s s}(n b)\right) \\
P_{P V, \text { low }} & \leq P_{P V} \leq P_{P V, \text { high }}
\end{aligned}
$$

where, $\boldsymbol{P}_{\boldsymbol{P V} \text {,high }}$ and $\boldsymbol{P}_{\boldsymbol{P V}, \text { low }}$ are the maximum and minimum power generation limits of PV.

2.2.3. Sizing Limits of Battery

$$
E_{B E S S, L} \leq E_{B E S S, j}(h) \leq E_{B E S S, H}
$$

where, $E_{B E S S, L}$ and $E_{B E S S, H}$ are the low and high magnitudes of battery energy stored.

\subsubsection{Line Constraints}

The current should be lower than the maximum current $\left(\boldsymbol{I}_{\max , b}\right)$ through the branch (b) [37].

$$
I_{b} \leq I_{m a x, b} b=1,2,3 \ldots, N b
$$

\subsection{Modeling and Sizing of PV and BES}

\subsubsection{Load Modelling}

The distribution network system studied in this paper have has various daily load demand configurations, such as residential load as shown if in Figure 2, industrial load as shown in Figure 3, and commercial load as indicated in Figure 4 [38,39]. All previous load demand patterns are based on the voltage and time with reactive and actual load voltage indexes. Time-varying load demands are modelled from Equations (15) and (16), as shown below [40]:

$$
\begin{aligned}
& P_{w}(t)=P_{o w}(t) \times V_{w}{ }^{N_{p}} \\
& Q_{w}(t)=Q_{o w}(t) \times V_{w}{ }^{N_{q}}
\end{aligned}
$$

where $Q_{k}$ and $P_{k}$ represent the reactive and real power at bus $k ; Q_{o k}$ and $\boldsymbol{P}_{\boldsymbol{o}}$ are the reactive and real load at bus $k$. $V_{k}$ represents the voltage at bus $k$, and $N_{q}$ and $N_{p}$ represent the reactive and real load voltage indices that are demonstrated in Table 1 [40].

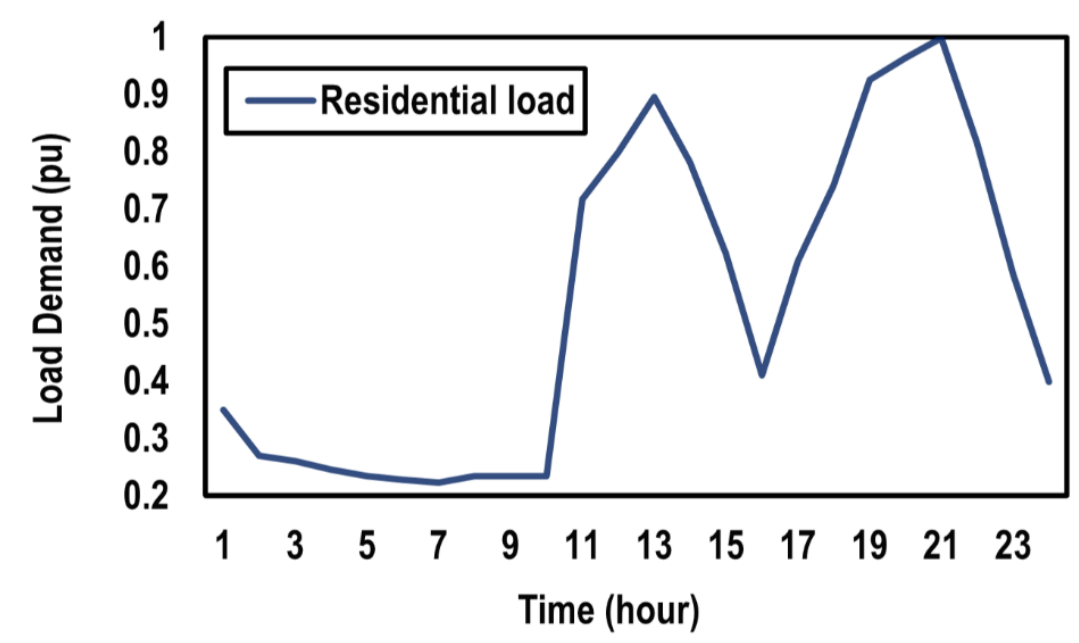

Figure 2. Normalized daily residential load demand curve. 


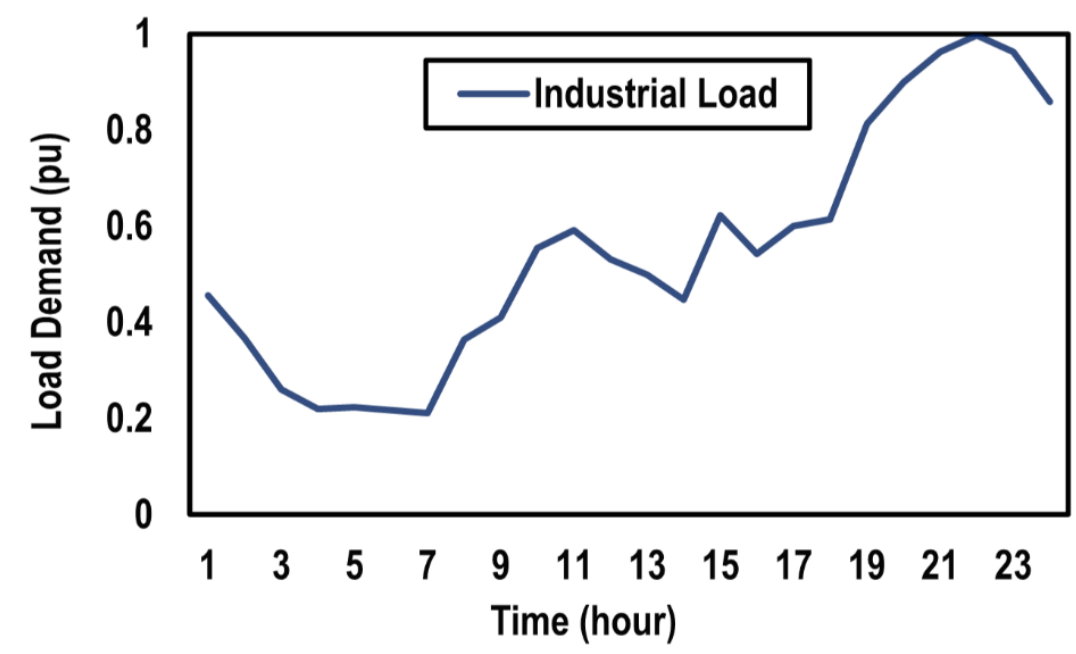

Figure 3. Normalized daily industrial load demand curve.

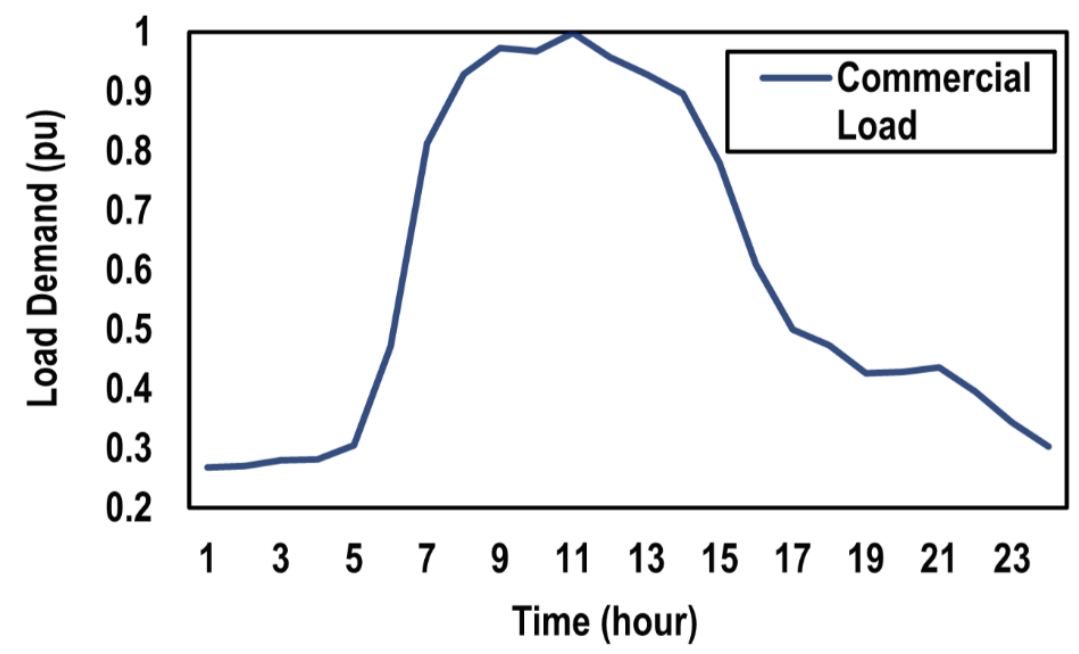

Figure 4. Normalized daily commercial load demand curve.

Table 1. The used parameters.

\begin{tabular}{|c|c|}
\hline The Used Parameters & The Proposed Value \\
\hline Number of search agents & 20 \\
\hline Maximum iteration & 2000 \\
\hline voltage limits & $0.9 \mathrm{pu} \leq V_{i} \leq 1.05 \mathrm{pu}$ \\
\hline $\begin{array}{c}\text { Limits of active output generation from PV with } \\
\text { BESS }\end{array}$ & $0.3 \mathrm{MW} \leq P_{P V+B E S, i} \leq 3 \mathrm{MW}$ \\
\hline $\begin{array}{l}\text { the real load voltage indices }\left(N_{p}\right) \text { for industrial, } \\
\text { residential and commercial load models }\end{array}$ & $0.18,0.92$ and 1.51 , respectively \\
\hline $\begin{array}{l}\text { the reactive load voltage indices }\left(N_{q}\right) \text { for } \\
\text { industrial, residential and commercial load models }\end{array}$ & $6,4.04$ and 3.4 , respectively \\
\hline
\end{tabular}




\subsubsection{PV Modelling}

The solar radiation probabilistic nature can be designated according to the probability density function (PDF) of Beta as follows [36,41]:

$$
f_{b}(s)=\left\{\begin{array}{c}
\frac{\Gamma(\alpha+\beta)}{\Gamma(\alpha) \Gamma(\beta)} s^{(\alpha-1)}(1-s)^{(\beta-1)} 0 \leq s \leq 1, \alpha, \beta \geq 0 \\
0 \text { otherwise }
\end{array}\right.
$$

where $f_{b}(s)$ refers to the s distribution function of Beta and s refers to the arbitrary variable of solar radiation in kilowatt per meter square; $\alpha$ and $\beta$ refer to the parameters of $f_{b}(s)$ which are computed exploiting the standard deviation $(\sigma)$ and mean deviation $(\boldsymbol{\mu})$ as shown in (18). The value of standard deviation and mean deviation are presented in [42].

$$
\beta=(1-\mu)\left(\frac{\mu(1+\mu)}{\sigma^{2}}-1\right) ; \alpha=\frac{\mu \times \beta}{1-\mu}
$$

The PV module output power output depends on the solar radiation and surrounding temperature as well as the PV module characteristics itself. The maximum output power related to solar radiation $s, \boldsymbol{P}_{\boldsymbol{o}}(\boldsymbol{s})$, can be expressed as [19]:

$$
P_{o}(s)=N \times F F \times V_{y} \times I_{y}
$$

where,

$$
\begin{gathered}
F F=\frac{V_{M P P} \times I_{M P P}}{V_{o c} \times I_{s c}} ; \\
V_{y}=V_{o c}-k_{v} \times T_{c y} ; \\
I_{y}=s\left[I_{s c}+k_{i} \times\left(T_{c}-25\right)\right] \\
T_{c y}=T_{A}+s\left(\frac{N_{O T}-20}{0.8}\right)
\end{gathered}
$$

where, $N$ refers to the module's number; $T_{c y}$ and $T_{A}$ refer to the cell temperature and ambient temperature $\left(C^{0}\right)$, respectively; $\mathrm{Ki}$ and $\mathrm{Kv}$ refer to the coefficient of current temperature $\left(\mathrm{A} / \mathrm{C}^{0}\right)$ and coefficient of voltage temperature $\left(\mathrm{V} / \mathrm{C}^{0}\right)$, respectively; FF refers to fill factor; NOT refers to rated working temperature of cell per $C^{0} ; I_{s c}$ and refer to short circuit current $(A)$ and open circuit voltage $(V)$, respectively; $V M P P$ and IMPP refer to voltage at maximum power point and current at maximum power point, respectively; $\boldsymbol{P}_{\boldsymbol{o}}(\boldsymbol{s})$ refers to the PV module maximum output power at solar radiation $(s)$. The prospective output power at solar radiation (s) is computed according to Equation (10). Therefore, the overall prospective output during the identified interval time $t, \boldsymbol{P}_{t}(\boldsymbol{t}=1 \mathrm{~h}$ in this study) can be expressed as follows:

$$
P_{t}=\int_{0}^{1} P_{o}(s) f_{b}(s) d s
$$

\subsubsection{BESS Modelling}

BESS is supposed to be linked to an alternating current (AC) system through bidirectional DC/AC converters [43]. In this paper, BESS works at unity power factor to discharge or charge active power. In another meaning, the BESS can work as a generator throughout the period of discharging and a load throughout the period of charging. The energy variation of BESS at bus $k$ in time interval $t$ is evaluated as the following [44]:

$$
\begin{gathered}
E_{B E S S k}(t)=E_{B E S S k}(t-1)-\frac{P_{B E S S k}^{d i s c h}(t)}{\eta_{d}} \Delta t, \text { for } P_{B E S S k}(t)>0 \\
E_{B E S S k}(t)=E_{B E S S k}(t-1)-\eta_{c} P_{B E S S k}^{c h}(t) \Delta t, \text { for } P_{B E S S k}(t) \leq 0
\end{gathered}
$$




$$
\eta_{B E S}=\eta_{C h} \times \eta_{D c h}
$$

where $E_{B E S S k}$ refers to the overall energy stored inside the BESS; $P_{B E S S k}^{\text {disch }}$ and $P_{B E S S k}^{c h}$ refer to the BESS discharged and charged power, respectively; $\eta_{d}$ and $\eta_{c}$ refer to the BESS efficiency in case of discharging and charging, respectively; $\Delta t$ indicates the duration of time interval $\mathrm{t}$.

\subsubsection{Sizing BES and PV}

BESS is installed at the same location of PV in RDS. Therefore, the optimal sizing of BESS with PV are presented in [42]. Therefore, the charging and discharging energies of batteries at time (t) are calculated by Equations (28) and (29).

$$
\begin{aligned}
& E_{B E S S, j}^{D C}=\int_{0}^{t} P_{B E S S, j}^{D C}(t) d t=\sum_{T=1}^{24} P_{B E S S_{, j}}^{D C}(t) \Delta t \\
& E_{B E S S, j}^{C}=\int_{0}^{t} P_{B E S S_{, j}}^{C}(t) d t=\sum_{t=1}^{24} P_{B E S S_{, j}}^{C}(t) \Delta t
\end{aligned}
$$

$\left(E_{(P V+B E S), j}\right)$ is a combination energy of BESS and PV at bus $(j)$ which is determined by Equation (30). PV energy is determined by Equation (31).

$$
\begin{gathered}
E_{(P V+B E S), j}=E_{P V, j}^{D S}+E_{B E S, j}^{D C} \\
E_{(P V), j}=E_{P V, j}^{D S}+E_{B E S, j}^{C}
\end{gathered}
$$

where $E_{B E S S, j}^{D C}$ is the discharging energy of BESS to the distribution system (DS). $E_{P V, j}^{D S}$ is the injection power energy from PV to DS and $E_{B E S S, j}^{C}$ the charging energy which is drawing from PV to BESS.

Round-trip efficiency can be determined by the ratio of discharging energy to the charging energy as shown below:

$$
\eta_{B E S}=\frac{E_{B E S, j}^{D C}}{E_{B E S, j}^{C}}
$$

Consequently, PV energy is updated to Equation (33) as follows:

$$
\begin{gathered}
E_{P V, j}=\frac{E_{(P V+B E S S), j}-\left(1-\eta_{B E S S}\right) E_{P V, j}^{G R}}{\eta_{B E S S}} \\
P_{P V, j}=K_{P V}^{o} E_{P V, j} \\
K_{P V}^{o}=\frac{P_{P V}^{o}}{E_{P V}^{o}}
\end{gathered}
$$

The high value of PV output during the day is evaluated by Equation (36).

$$
P_{P V, j}=K_{P V}^{o}\left(\frac{E_{(P V+B E S S), j}-\left(1-\eta_{B E S S}\right) E_{P V, j}^{G R}}{\eta_{B E S S}}\right)
$$

where, $E_{P V}^{o}$ and $P_{P V}^{o}$ are the energy and maximum output of PV during the day, respectively. BESS sizing is determined by Equation (37).

$$
E_{B E S, j}^{C h}=\frac{E_{(P V+B E S), j}-E_{P V, j}^{G r}}{\eta_{B E S}}
$$




\section{Optimization Methodology}

\subsection{Frame Design}

In general, the recommended Archimedes optimization algorithm describes what occurs when objects that have different volumes and weights are dipped into a liquid. The following subsections indicate how the AOA was based on the phenomena elucidated in Archimedes' principle. Then, we explain how this law of physics is applied along with an algorithm of optimization [45].

\subsubsection{Principle of Archimedes}

The Archimedes principle declares that when dipping an object partially or completely into a liquid, the liquid goes flat out at an upward force on this object equivalent to liquid's weight dislodged by this object. Figure 5 describes that when an object is dipped into a liquid, it will be exposed to an upward force, named buoyant force, equivalent to the weight of the liquid dislodged by this object [46].

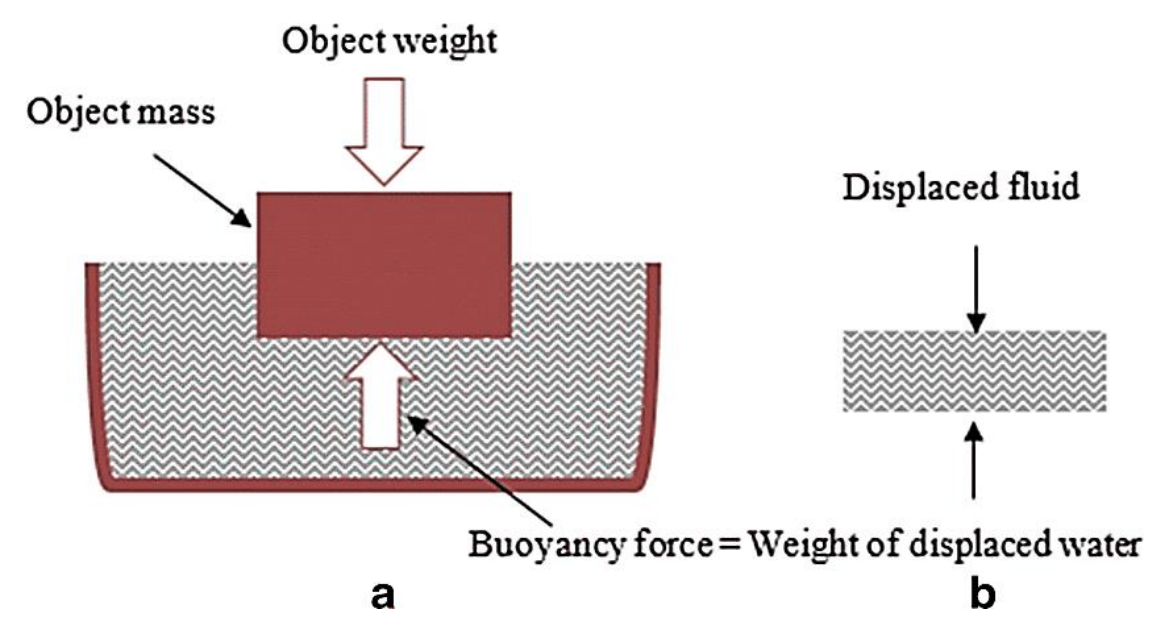

Figure 5. (a) An object is dipped into a liquid, and (b) the volume of liquid dislodged [45].

\subsubsection{Theory}

Figure 6 indicates when some objects dipped into the same liquid and every one attempts to achieve the state of equilibrium. The speed at which each immersed object reaches to the state of equilibrium varies due to its different density and volume. Any object will be in the state of equilibrium when the buoyant force $\boldsymbol{F}_{\boldsymbol{b}}$ is equivalent to the weight $\left(\boldsymbol{W}_{\boldsymbol{o}}\right)$ of this object:

$$
\begin{aligned}
F_{b} & =W_{o} \\
\rho_{b} v_{b} a_{b} & =\rho_{O} v_{O} a_{O}
\end{aligned}
$$

where $\rho_{b}$ and $\rho_{o}$ are the density of the liquid and the dipped object, respectively, $v_{b}$ and $v_{o}$ are the volume of the liquid and the dipped object, respectively, and $\boldsymbol{a}_{\boldsymbol{o}}$ and $\boldsymbol{a}_{\boldsymbol{b}}$ are the gravity or acceleration of the liquid and the dipped object, respectively. This previous equation can be reorganized as the following:

$$
a_{o}=\frac{\rho_{b} v_{b} a_{b}}{\rho_{o} v_{o}}
$$




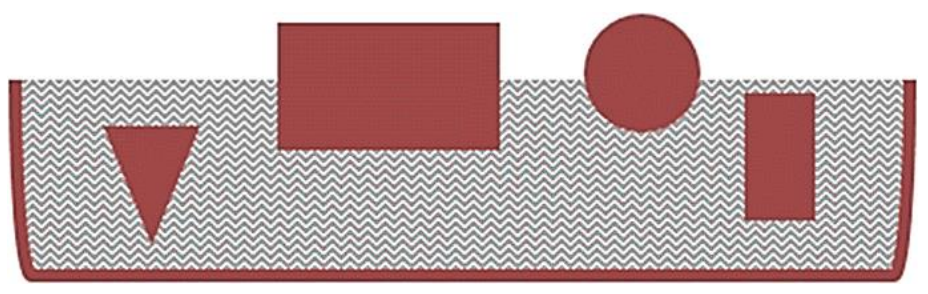

Figure 6. Some objects dipped in the same liquid [45].

In the case of presence of another force acting on the object, such as colliding with another adjacent object $(r)$, then the state of equilibrium will be:

$$
\begin{gathered}
F_{b}=W_{o}, \\
W_{b}-W_{r}=W_{o} \\
\rho_{b} v_{b} a_{b}-\rho_{r} v_{r} a_{r}=\rho_{0} v_{0} a_{0}
\end{gathered}
$$

\subsection{Archimedes Optimization Algorithm}

$\mathrm{AOA}$ is an algorithm that depends on a population. In this algorithm, the individuals of the population are the dipped objects. Resembling other metaheuristic algorithms that depend on population, AOA likewise initiates search procedure with preliminary population of objects, called candidate solutions, with arbitrary densities, accelerations, and volumes. At this phase, every object is likewise started with its arbitrary situation in liquid. Afterward, assessing the fitness of preliminary population, AOA works in repetitions until the end limit is achieved. After each repetition, AOA modernizes the volume and density for each object. The object's acceleration is modernized based on the state of collision with any other nearby object. Modernizing, density, acceleration and volume define the object's new location. In the following sub-section, the mathematical expression steps for AOA are explained.

\section{Steps of AOA Algorithm}

The mathematical construction for the algorithm of AOA is presented in this subsection. Theoretically, AOA is deemed as a universal algorithm where it involves both exploitation and exploration procedures. The pseudocode of the AOA is indicated in Algorithm 1; it includes the preliminary population of objects, population assessment, and modernizing parameters. Mathematically, the stages of the suggested AOA are indicated as follows:

1 Preparation Set the locations of overall objects using (44):

$$
O_{i}=l b_{i}+\operatorname{rand}(i, \operatorname{Dim}) \times\left(u b_{i}-l b_{i}\right), i=1,2, \ldots . ., N
$$

where $O_{i}$ refers to the ith object from the population that have $N$ (search agents) objects. $\boldsymbol{u} \boldsymbol{b}_{\boldsymbol{i}}$ and $\boldsymbol{l} \boldsymbol{b}_{\boldsymbol{i}}$ are the higher and lower limits of the search scope, respectively. Dim represents the dimension variables.

Set the initial value of density (den) and volume (vo) for every ith object according to Equations (45) and (46).

$$
\begin{aligned}
& \operatorname{den}_{i}=\operatorname{rand}(i, \operatorname{Dim}) \\
& \operatorname{vol}_{i}=\operatorname{rand}(i, \operatorname{Dim})
\end{aligned}
$$

where rand refers to a random number within $[0,1]$. Finally, set the initial value of ith object acceleration (acc) using (47):

$$
a c c_{i}=l b_{i}+\operatorname{rand}(i, \operatorname{Dim}) \times\left(u b_{i}-l b_{i}\right)
$$


In this step, assess preliminary population and nominate the object that has the best fitness value. Specify, the best location $\left(x_{\text {best }}\right)$, the best density $\left(\right.$ den $\left._{\text {best }}\right)$, the best volume $\left.\left(v_{\text {best }}\right)\right)$, and the best acceleration $\left(\operatorname{acc}_{\text {best }}\right)$.

2 Modernize volumes and densities The volume and the density for every object $i$ at the repetition $(t+1)$ is modernized according to (48) and (49):

$$
\begin{gathered}
\operatorname{vol}_{i}^{t+1}=\operatorname{vol}_{i}^{t}+\operatorname{rand} \times\left(\operatorname{vol}_{b s e t}-\operatorname{vol}_{i}^{t}\right) \\
\operatorname{den}_{i}^{t+1}=d e n_{i}^{t}+\operatorname{rand} \times\left(\operatorname{den}_{b s e t}-\operatorname{den}_{i}^{t}\right)
\end{gathered}
$$

where $v l_{b s e t}$ is the volume correlated to the best object that has been obtained so far, and rand is a random number that is distributed uniformly.

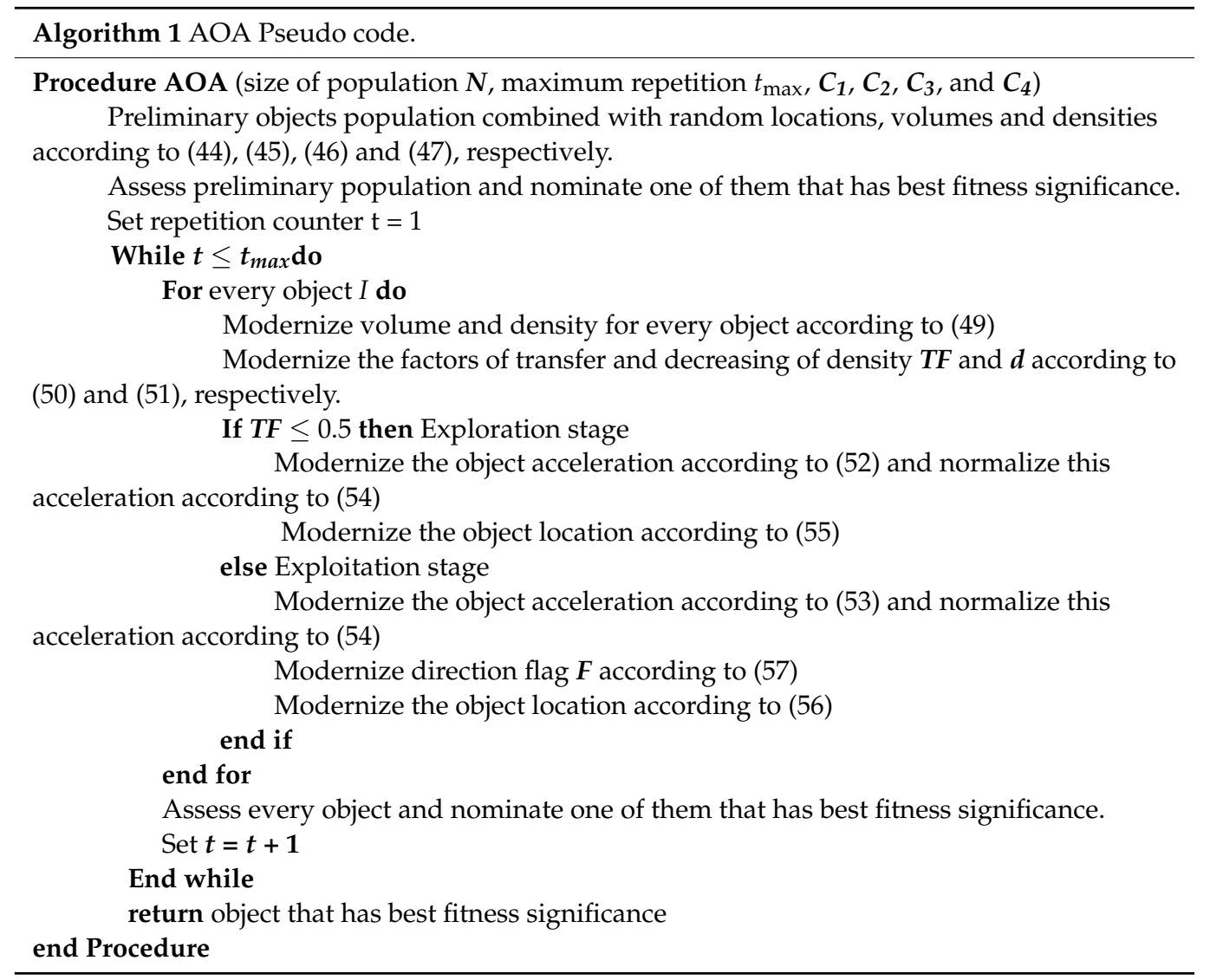

3 In the AOA algorithm, the population objects (search agents) are searching for the best promising area in all of the search space by the exploration phase and then searching for the best location (best object) in this promising area by the exploitation phase. TF is a factor that is changing with iteration to transfer the algorithm from the exploration phase to the exploitation phase through the simulation time, and can be evaluated as follows:

$$
T F=\exp \left(\frac{t-t_{\max }}{t_{\max }}\right)
$$

where the TF factor rises progressively with increasing time till up to $1 ; \boldsymbol{t}_{\text {max }}$ and $\boldsymbol{t}$ are the maximum repetitions number and repetition number, respectively. Likewise, density decreasing factor $\mathrm{d}$ also supports the proposed AOA on universal to local inspection. It reduces with increasing time according to (51):

$$
d^{t+1}=\exp \left(\frac{t_{\max }-t}{t_{\max }}\right)-\left(\frac{t}{t_{\max }}\right)
$$


where $d^{t+1}$ reduces with increasing time that provides the capability to converge in the previously specified promising zone. To guarantee a balance between the exploration and the exploitation in the proposed AOA, this variable must be handled appropriately. The text continues here.

4 Exploration step (colliding among objects happens). If $T F \leq 0.5$, colliding among objects happens, an arbitrary material $(m r)$ must be nominated and the acceleration of for repetition $t+1$ according to (52) must be modernized:

$$
\operatorname{acc}_{i}^{t+1}=\frac{\operatorname{den}_{m r}+v o l_{m r} \times a c c_{m r}}{d e n_{i}^{t+1} \times \operatorname{vol}_{i}^{t+1}}
$$

where $a c c_{i}, \boldsymbol{d e n}_{i}$, and $v o l_{i}$ are the acceleration, the density, and the volume of the object $I$, whereas $a c c_{m r}, v o l_{m r}$ and $d e n_{m r}$ are the acceleration, the volume, and the density of arbitrary material. It is significant to indicate that $\boldsymbol{T F} \leq 0.5$ guarantees exploration through one third of repetitions. Using a value other than 0.5 will affect the behavior of changing from exploration to exploitation steps.

5 Exploitation step (no colliding among objects). If $\boldsymbol{T F}>0.5$, there is no colliding among objects, modernize the acceleration of the object for repetition $(t+1)$ according to (53):

$$
\operatorname{acc}_{i}^{t+1}=\frac{\operatorname{den}_{\text {best }}+\operatorname{vol}_{\text {best }} \times \operatorname{acc}_{\text {best }}}{\operatorname{den}_{i}^{t+1} \times \operatorname{vol}_{i}^{t+1}}
$$

where $a c_{\text {best }}$ refers to the best object acceleration.

6 Normalize the object acceleration. Normalize the object acceleration to compute the percentage of variation according to (54):

$$
a c c_{i-n o r m}^{t+1}=u \times \frac{a c c_{i}^{t+1}-a c c_{\min }}{a c c_{\max }-a c c_{\min }}+l
$$

where $l$ and $u$ represent the scope of normalization and put it at 0.1 and 0.9 , respectively. The $a c c_{i-n o r m}^{t+1}$ calculates the percentage of the period that every agent will alteration. The value of acceleration will be great when the object is away from the global optimum, which means that the object will be in the exploration stage; other than that, it will be in the exploitation stage. This clarifies how the inspection modifies from the exploration stage to the exploitation stage. In an ordinary case, the factor of acceleration initiates with high value and reduces with increasing time. This aids search agents to move away from local solutions and at the same time transfer towards the global best solution. However, it is significant to state that there may still a small number of search agents that require extra time to stay in the exploration stage than in the normal case. Therefore, the proposed AOA attains the equilibrium between the exploration stage and the exploitation stage.

7 Modernize location If $T F \leq 0.5$ (exploration stage), the $i$ th object's location for following repetition $t+1$ according to (55)

$$
x_{i}^{t+1}=x_{i}^{t}+C_{1} \times \text { rand } \times a c c_{i-n o r m}^{t+1} \times d \times\left(x_{\text {rand }}-x_{i}^{t+1}\right)
$$

where $C_{1}$ referes to a constant that equals 2 . Other than that, when $T F>0.5$ (exploitation stage), the objects modernize their locations according to (56).

$$
x_{i}^{t+1}=x_{\text {best }}^{t}+F \times C_{2} \times \text { rand } \times \operatorname{acc}_{i-\text { norm }}^{t+1} \times d \times\left(T \times x_{\text {best }}-x_{i}^{t}\right)
$$

where $C_{2}$ referes to a constant that equals 6 . T rises with increasing time and it is proportional to transfer factor and it is determined according to $T=C_{3} \times T F$. Additionally, it rises with increasing time through the scope $\left[C_{3} \times 0.3,1\right]$ and it possesses a particular percentage from the best location, at first. It begins with small percentage which causes a huge difference between the best location and the present location; consequently, the random 
walk step-size will be big. As the search continues, this percentage will rise progressively to reduce the difference between the best location and the present location. This results in an appropriate equilibrium between the exploration and the exploitation. $\boldsymbol{F}$ is the flag to vary the motion direction according to (57):

$$
F=\left\{\begin{array}{l}
+1 \text { if } P \leq 0.5 \\
-1 \text { if } P>0.5
\end{array}\right.
$$

where $\mathbf{P}=\mathbf{2} \times$ rand $-C_{4}$.

8 Assessment Assess every object exploiting function $\mathrm{f}$ and recollect the best solution found yet. Designate $x_{\text {best }}, v^{o l_{\text {best }}}$, den $_{\text {best }}$, and $\boldsymbol{a c c}$ best .

\section{Simulation Results and Dissections}

The IEEE 69-bus radial distribution system (RDS) includes 69 buses with a reactive load of $2694.6 \mathrm{kVAr}$ and an active load of $3801.5 \mathrm{~kW}$ as shown in Figure 7 [47]. The results are obtained under base values of $12.66 \mathrm{kV}$ and 10 MVA. The used parameters and the system constraints are given in Table 1 . This paper studies the optimal allocation of PV alone or with BES in residential, industrial, and commercial system loads.

\subsection{Residential Load}

In this case, the overall reactive and real load demand during $24 \mathrm{~h}$ are $34.43 \mathrm{MVAr}$ and 48.57 MW, respectively. Without integration PV and BES in RDS, the total reactive and real loss during $24 \mathrm{~h}$ are $0.85 \mathrm{MVAr}$ and $1.87 \mathrm{MW}$, respectively. Installing one PV alone in RDS at bus 61 reduces the system loss to $1.39 \mathrm{MW}$. Additionally, installing two PV alone in RDS at buses 61 and 17 reduces the system loss to $1.35 \mathrm{MW}$. The total energies of one and two PV alone in RDS during the day are illustrated in Figures 8 and 9. Table 2 illustrates the locations and sizes of PV, the total energy of PV, and the injection energy from PV to the grid. Therefore, installing three PV alone reduces the system loss to 1.34 MW at buses 61,18 , and 11. From Figure 10, the total energy of three PV alone is 15.64 MWh.

From Table 3, simultaneous integration of PV and BES gives better results than integration of PV alone in RDS. Installing one BESS and PV in RDS decreases the system loss to $0.71 \mathrm{MW}$ at bus 61 . The energies of PV and BESS during the day by incorporating one PV with BESS in RDS are illustrated in Figures 11 and 12. Installing two and three PV with BES in RDS decrease the system loss to $0.61 \mathrm{MW}$ and $0.59 \mathrm{MW}$, respectively. The energies of PV and BESS during the day by incorporating two PV with BESS in RDS are illustrated in Figures 13 and 14. Additionally, energies of PV and BESS during the day by incorporating three PV with BESS in RDS are illustrated in Figures 15 and 16. Table 3 illustrates the locations and sizes of PV and BESS, the total energy of PV, the injection energy from PV to the grid, the charging energy from PV to BESS, and the discharging energy from BESS to the grid. 


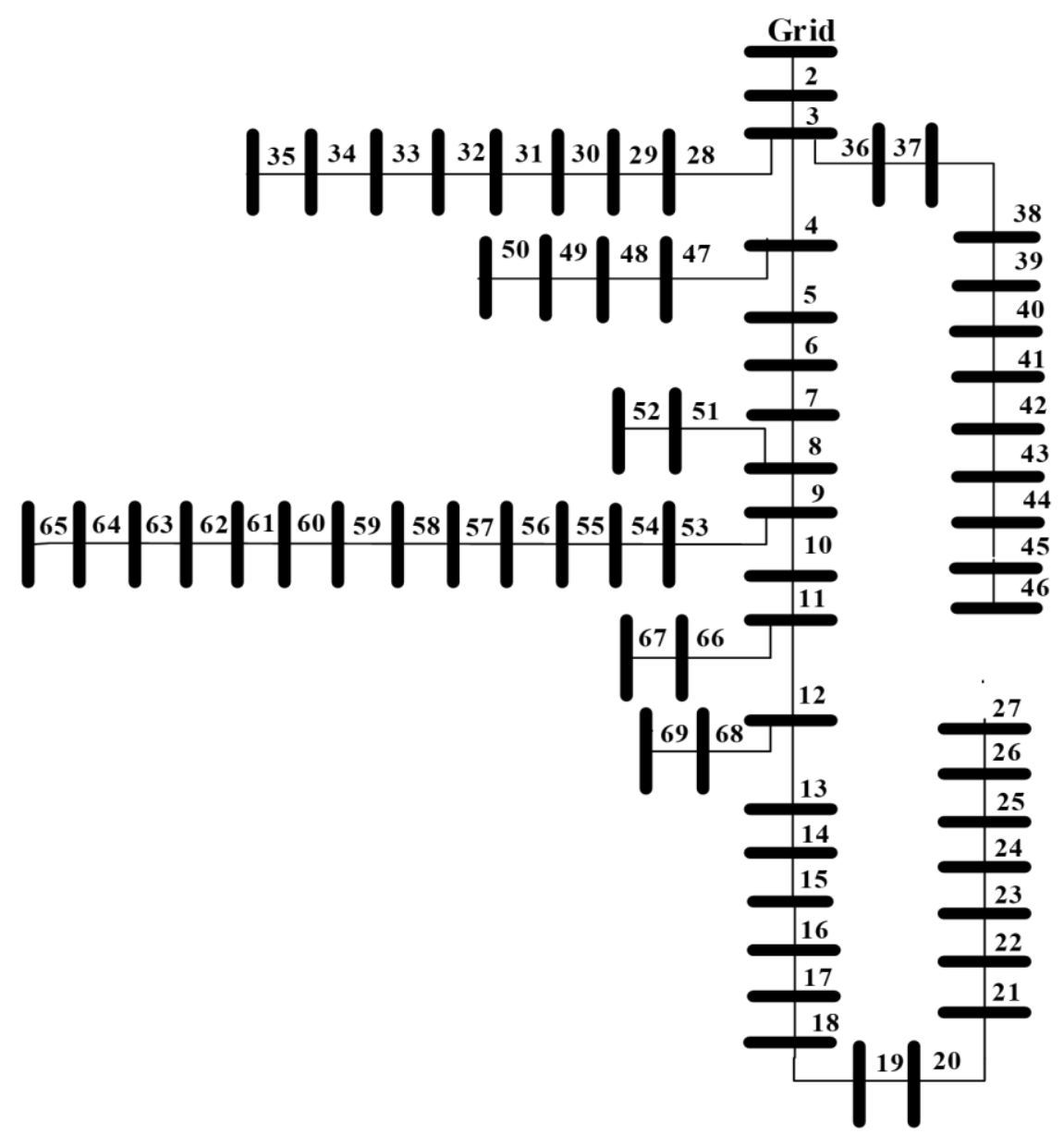

Figure 7. IEEE 69-bus RDS.

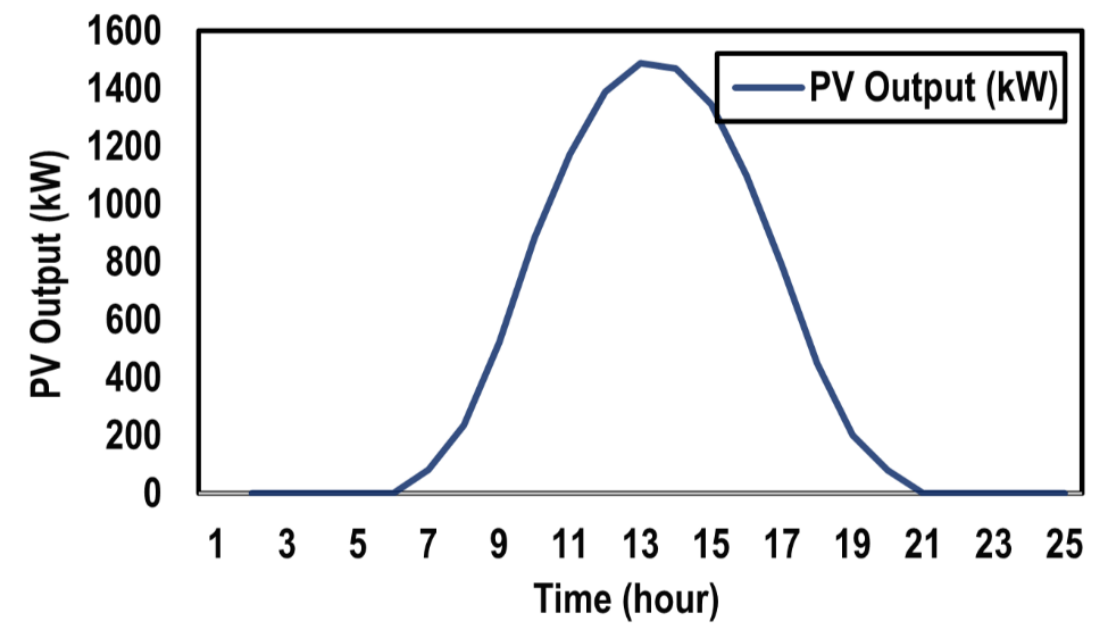

Figure 8. PV output during the day by installing one PV alone in residential system load. 


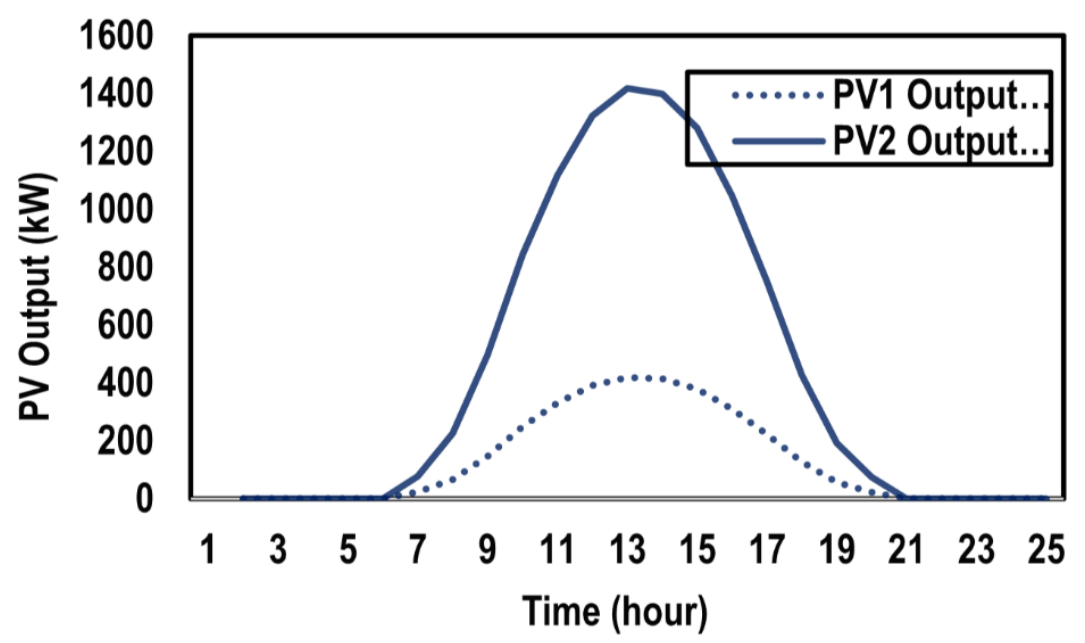

Figure 9. PV output during the day by installing two PV alone in residential system load.

Table 2. The obtained results with and without installing PV alone in residential system loads.

\begin{tabular}{|c|c|c|c|c|c|}
\hline \multicolumn{2}{|c|}{ Item } & Position (Size (kW)) & PV Energy (kWh) & Total PV Energy (kWh) & $\mathbf{P}_{\text {loss }}(\mathbf{k W})$ \\
\hline \multirow{6}{*}{$\begin{array}{l}\text { Residential } \\
\text { Load }\end{array}$} & Without PV & - & - & - & 1867.977 \\
\hline & 1-PV & $61(1489)$ & $61(11,207)$ & 11,207 & 1389.4 \\
\hline & \multirow[t]{2}{*}{ 2-PV } & 61 (1417.5) & $61(10,668)$ & \multirow[t]{2}{*}{$13,823.3$} & \multirow[t]{2}{*}{1349.2} \\
\hline & & $\begin{array}{c}17(419.2) \\
61(1369)\end{array}$ & $\begin{array}{l}17(3155.3) \\
61(10,304)\end{array}$ & & \\
\hline & \multirow[t]{2}{*}{ 3-PV } & $18(302.8)$ & $18(2279)$ & \multirow[t]{2}{*}{$15,639.6$} & \multirow[t]{2}{*}{1341.6} \\
\hline & & $11(406.1)$ & $11(3056.6)$ & & \\
\hline
\end{tabular}

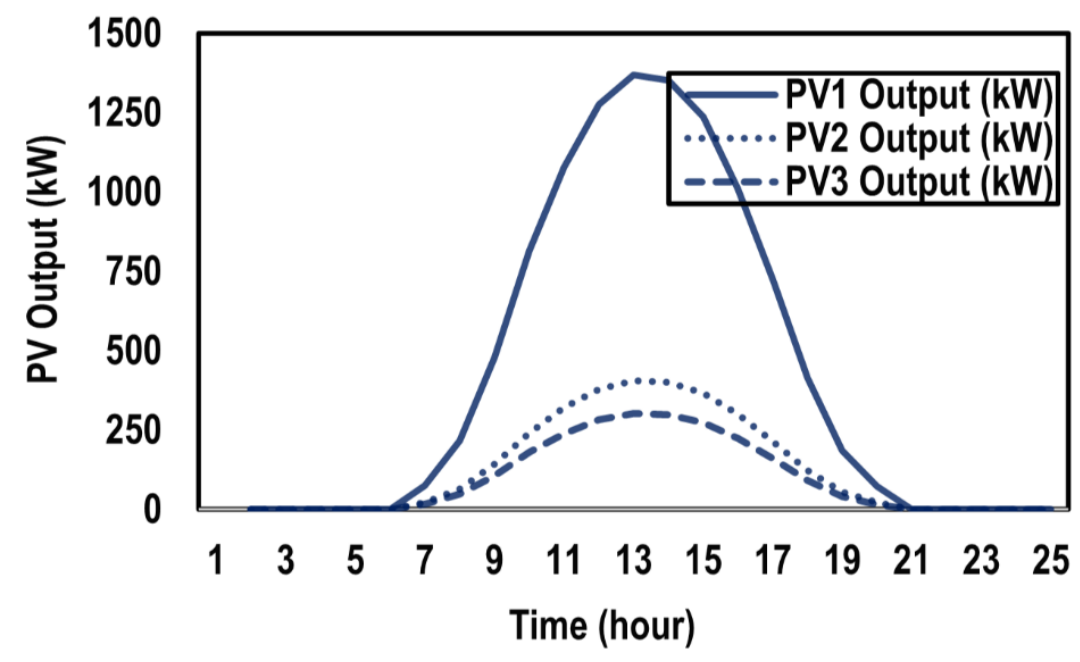

Figure 10. PV output during the day by installing three PV alone in residential system load. 
Table 3. The obtained results with and without installing PV with BES in residential system loads.

\begin{tabular}{|c|c|c|c|c|c|c|c|c|}
\hline \multicolumn{3}{|c|}{ Item } & $\begin{array}{c}\text { Position } \\
(\text { Size }(k W))\end{array}$ & $\begin{array}{l}\text { PV Energy } \\
\text { (kWh) }\end{array}$ & $\begin{array}{c}\text { EPV to grid } \\
\text { (kWh) }\end{array}$ & $\begin{array}{c}\text { Charging } \\
\text { Energy } \\
(\mathrm{kWh})\end{array}$ & $\begin{array}{c}\text { Discharging } \\
\text { Energy } \\
(\mathrm{kWh})\end{array}$ & $\begin{array}{l}P_{\text {loss }} \\
(\mathbf{k W})\end{array}$ \\
\hline \multirow{12}{*}{$\begin{array}{l}\text { Residential } \\
\text { Load }\end{array}$} & \multicolumn{2}{|c|}{$\begin{array}{c}\text { Without } \\
\text { PV and BES }\end{array}$} & - & - & - & - & - & 1867.977 \\
\hline & 1 & $\begin{array}{l}\text { PV } \\
\text { BES }\end{array}$ & $\begin{array}{l}61(3693.2) \\
61(2467.5)\end{array}$ & $\begin{array}{c}27796 \\
-\end{array}$ & $\begin{array}{c}11666 \\
-\end{array}$ & 16,130 & 12,358 & 711.9071 \\
\hline & \multirow{4}{*}{2} & \multirow{2}{*}{ PV } & $61(3466.1)$ & $61(26,088)$ & $61(10,971)$ & & (12, & \multirow{3}{*}{613.1804} \\
\hline & & & $17(1163.1)$ & $17(7797.1)$ & $17(3279.6)$ & - & - & \\
\hline & & \multirow{2}{*}{ BES } & $61(2323)$ & & \multirow[t]{2}{*}{$18(027.0)$} & $61(15,116)$ & $61(11,581)$ & \\
\hline & & & 17 (693.992) & & & 17 (4517.5) & $17(3460.9)$ & \multirow{7}{*}{594.447} \\
\hline & \multirow{6}{*}{3} & \multirow{3}{*}{ PV } & $61(3345.6)$ & $61(25,180)$ & $61(10,589)$ & & & \\
\hline & & & $18(745.66)$ & $18(5612.2)$ & $18(2361.7)$ & - & - & \\
\hline & & & $11(1012.7)$ & $11(7622.3)$ & $11(3202.5)$ & & & \\
\hline & & \multirow{3}{*}{ BES } & $61(2242.17)$ & & & $61(14,591)$ & $61(11,178)$ & \\
\hline & & & $18(498.78)$ & - & - & $18(3250.5)$ & $18(2490.2)$ & \\
\hline & & & $11(681.1)$ & & & $11(4419.8)$ & $11(3386)$ & \\
\hline
\end{tabular}

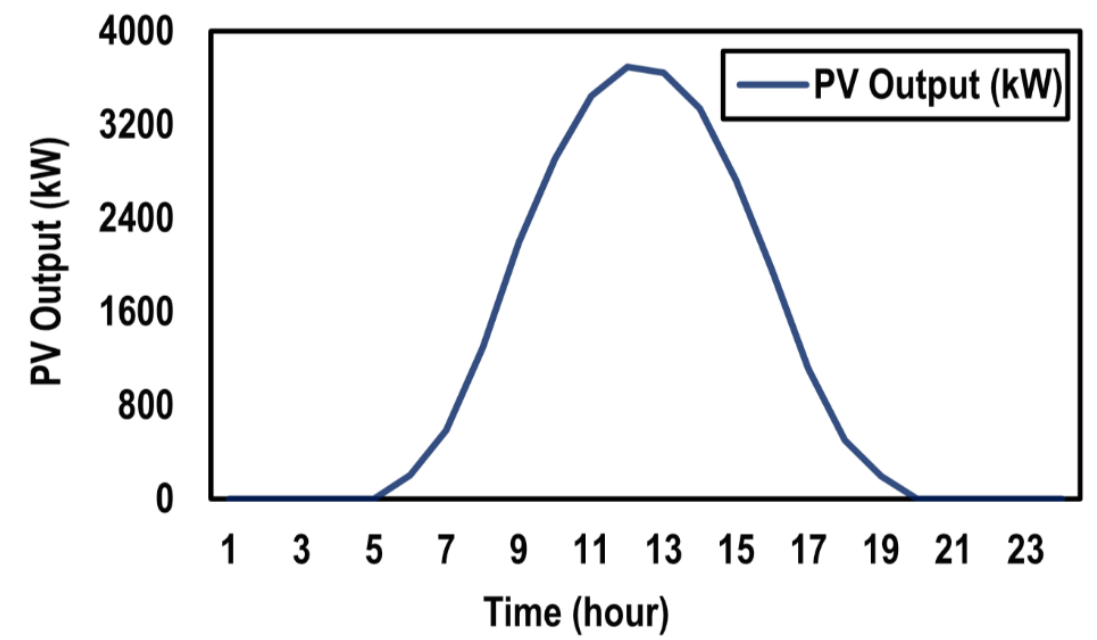

Figure 11. PV output during the day by installing one PV with BES in residential system load.

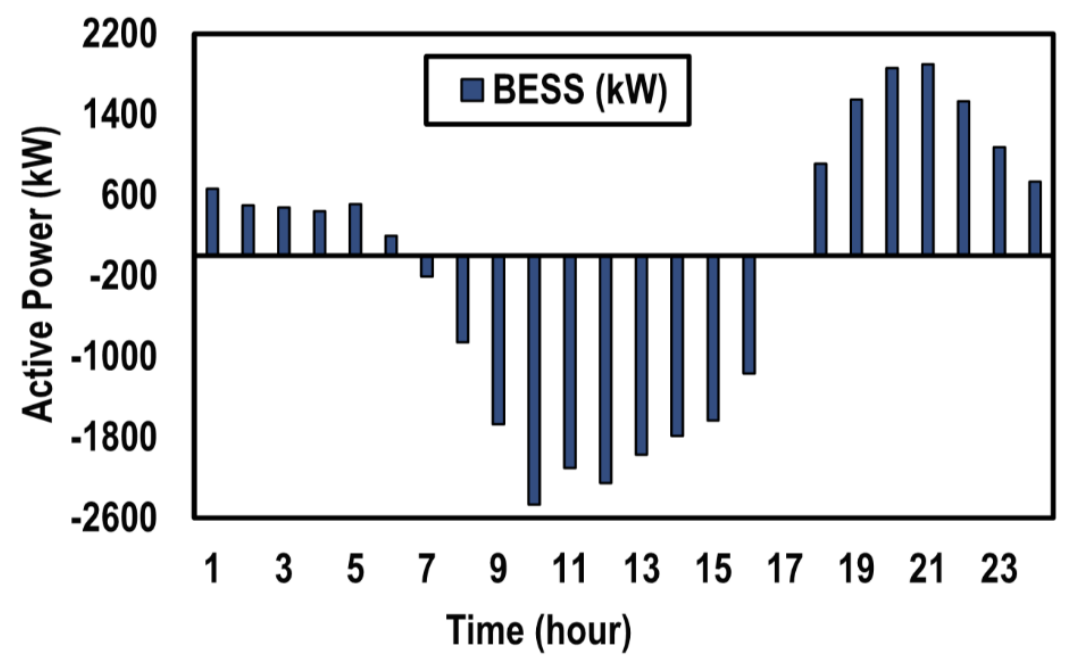

Figure 12. BES output during the day by installing one PV with BES in residential system load. 


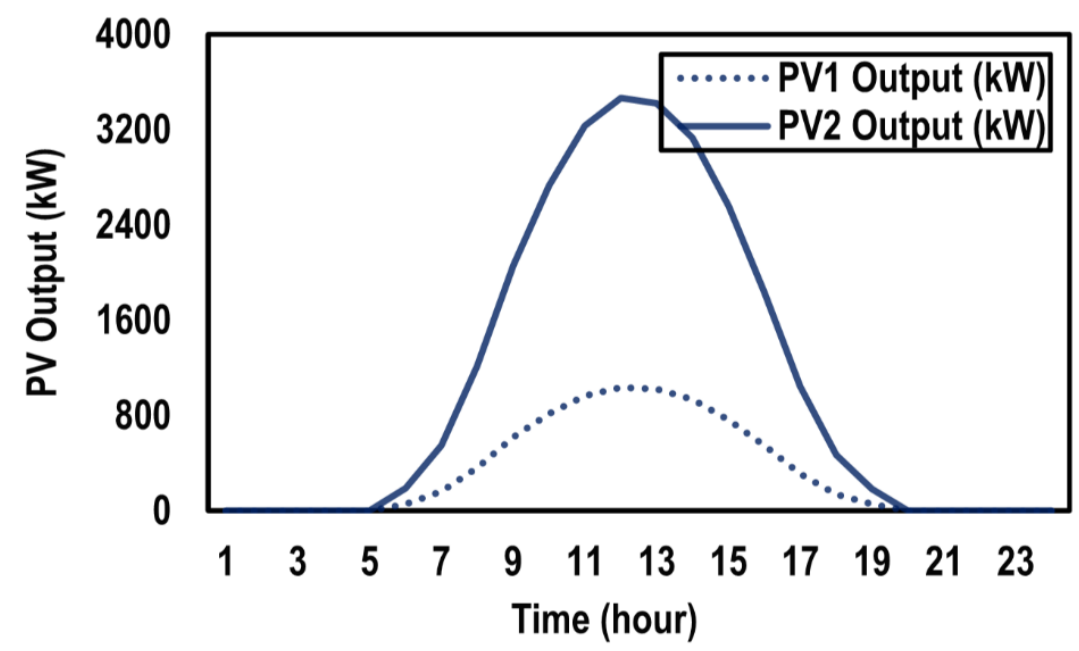

Figure 13. PV output during the day by installing two PV with BES in residential system load.

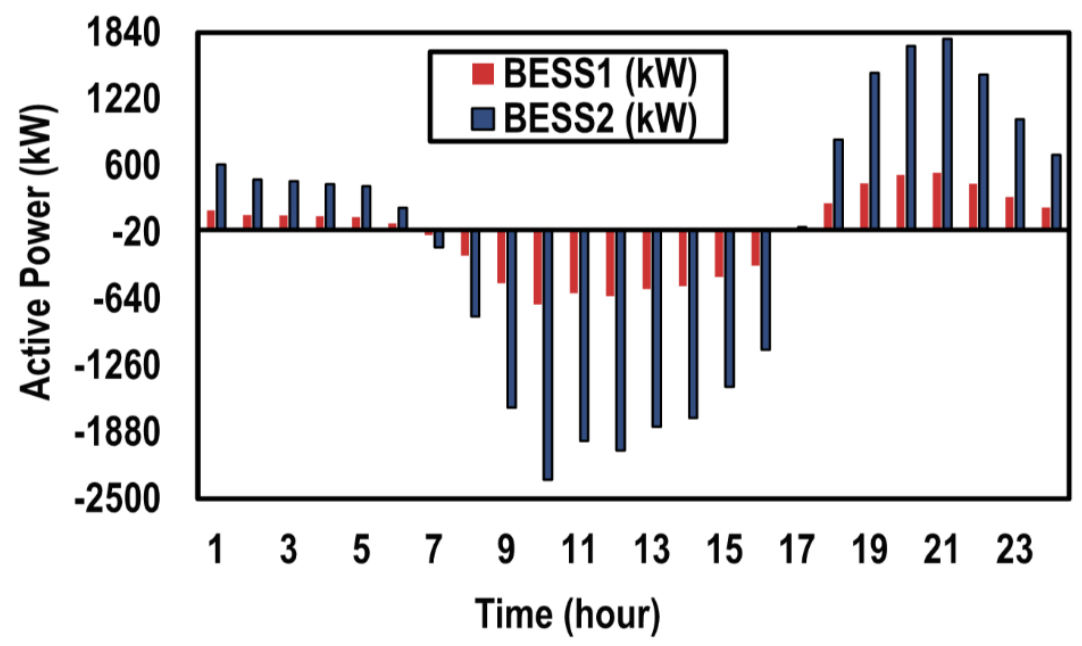

Figure 14. BES output during the day by installing two PV with BES in residential system load.

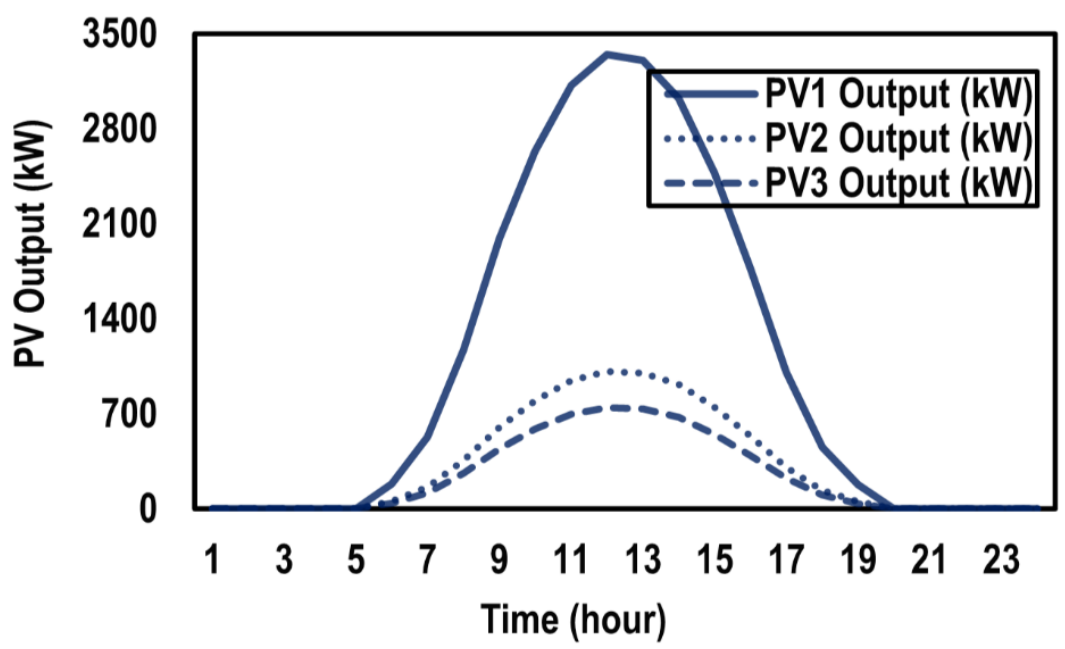

Figure 15. PV output during the day by installing three PV with BES in residential system load. 


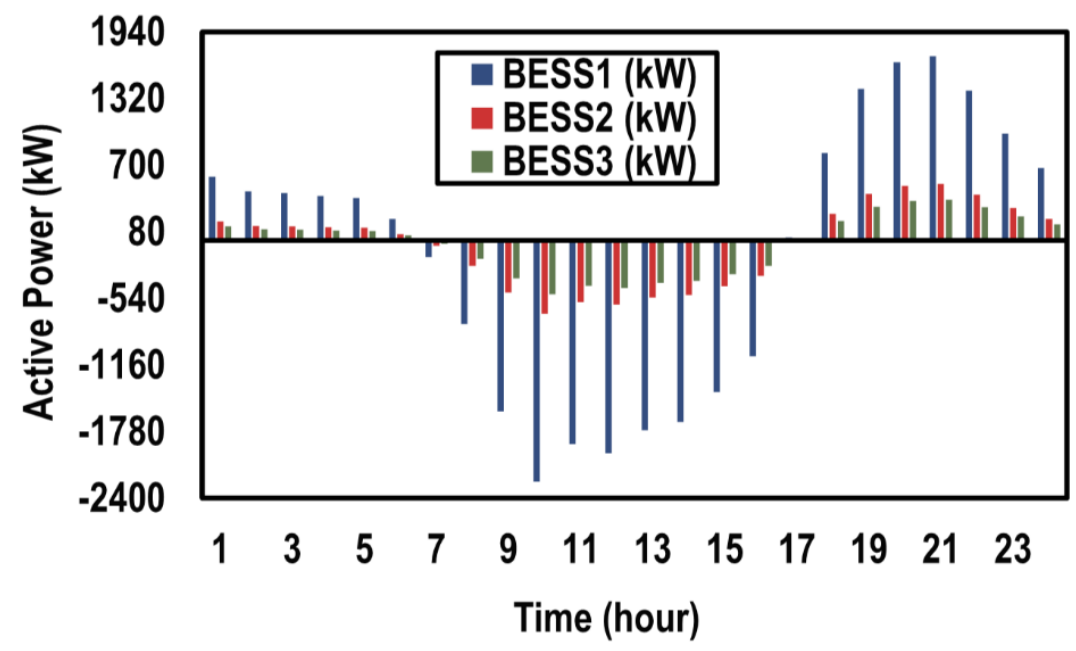

Figure 16. BES output during the day by installing three PV with BES in residential system load.

\subsection{Industrial Load}

In this case, the overall reactive and real load demand during $24 \mathrm{~h}$ are $35.64 \mathrm{MVAr}$ and 50.29 MW, respectively. Without integrating PV and BES in RDS, the total active and reactive power loss during $24 \mathrm{~h}$ are $1.89 \mathrm{MW}$ and $0.86 \mathrm{MVAr}$, respectively. The total system losses are decreased to $1.55 \mathrm{MW}, 1.52 \mathrm{MW}$, and $1.52 \mathrm{MW}$ by integrating one, two, and three PV alone in RDS, respectively. Table 4 presents the locations and sizes of PV, the total energy of PV, the injection energy from PV to the grid and the system power loss. From Figures 17 and 18, the total energies of one and two PV alone during the day are $9.56 \mathrm{MWh}$ and $11.80 \mathrm{MWh}$, respectively. Additionally, the total energy of three PV alone during the day is 13.35 MWh as shown in Figure 19.

Table 4. The obtained results with and without installing PV alone in industrial system loads.

\begin{tabular}{|c|c|c|c|c|c|}
\hline \multicolumn{2}{|c|}{ Item } & Position (Size (kW)) & PV Energy (kWh) & Total PV Energy (kWh) & $P_{\text {loss }}(\mathbf{k W})$ \\
\hline \multirow{6}{*}{$\begin{array}{l}\text { Industrial } \\
\text { Load }\end{array}$} & Without PV & - & - & - & 1890.1117 \\
\hline & 1-PV & $61(1270.7)$ & $61(9563.6)$ & 9563.6 & 1553.5 \\
\hline & 2-PV & $\begin{array}{c}61(1209.5) \\
17(358.8)\end{array}$ & $\begin{array}{l}61(9102.9) \\
17(2700.9)\end{array}$ & $11,803.8$ & 1524.4 \\
\hline & & $61(1168)$ & $61(8790.6)$ & & \\
\hline & 3-PV & $18(259.6)$ & 18 (1954.1) & $13,348.4$ & 1518.93 \\
\hline & & $11(345.9)$ & 11 (2603.7) & & \\
\hline
\end{tabular}

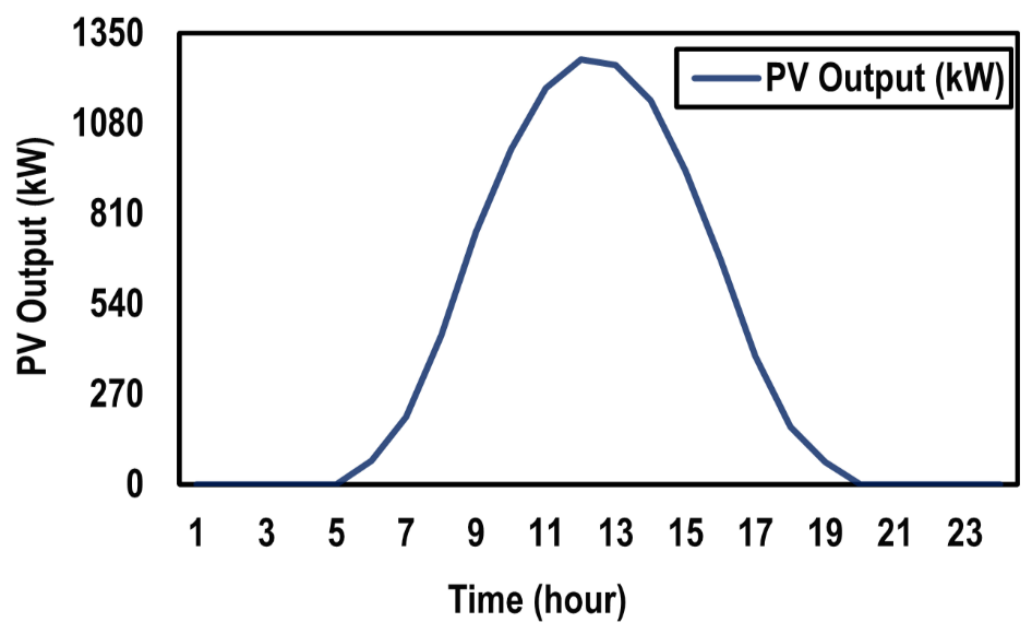

Figure 17. PV output during the day by installing one PV alone in industrial system load. 


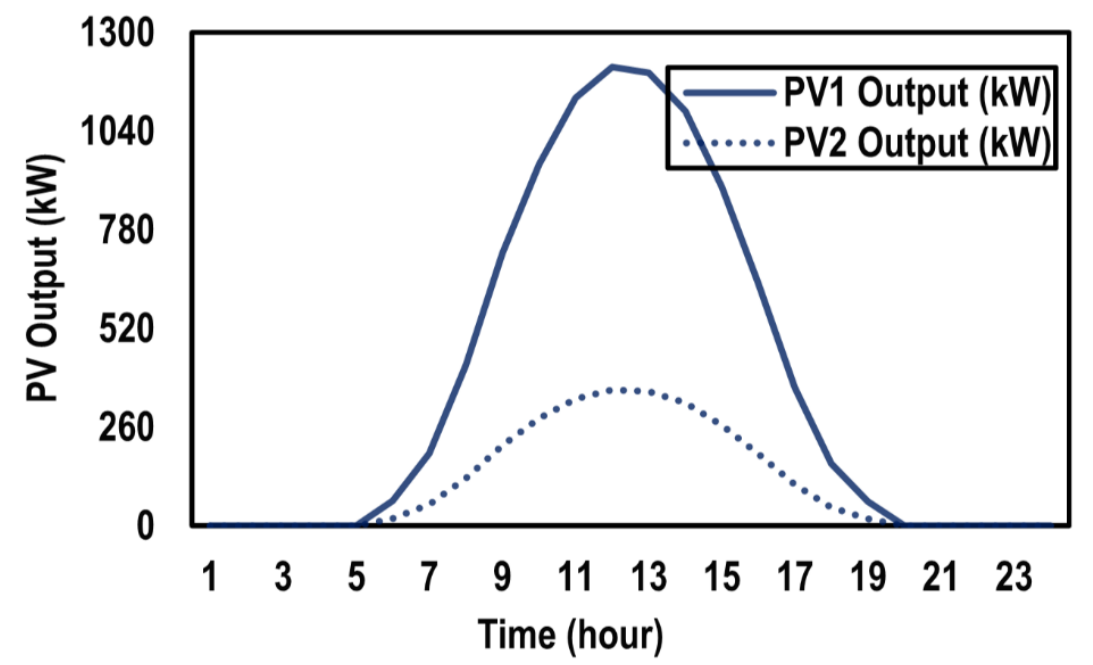

Figure 18. PV output during the day by installing two PV alone in industrial system load.

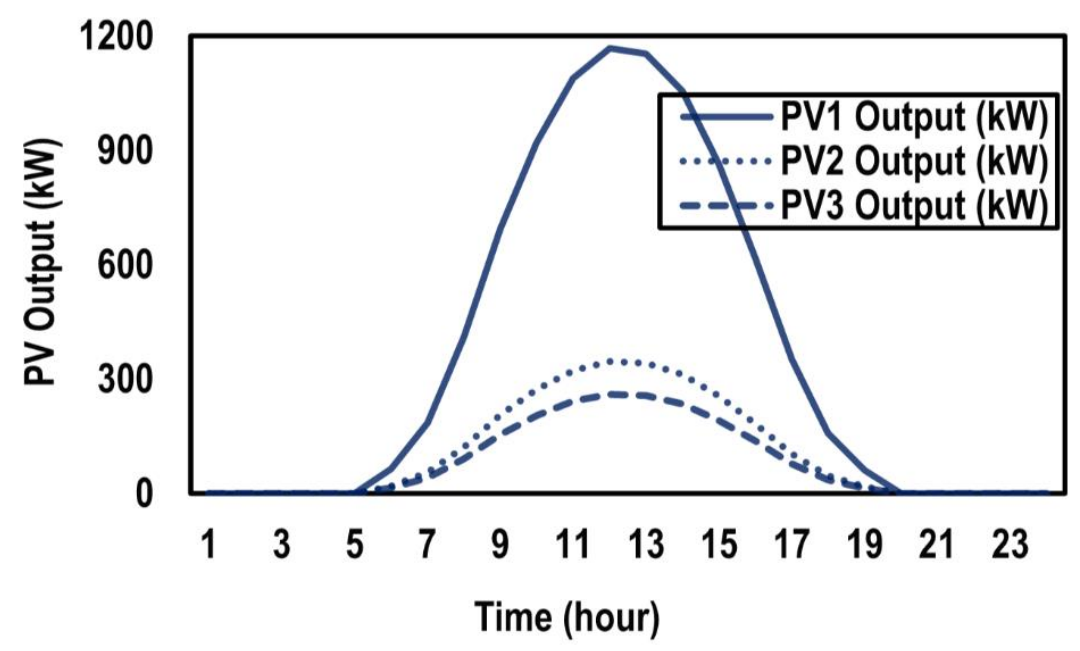

Figure 19. PV output during the day by installing three PV alone in industrial system load.

The optimal allocation of one PV with BES in RDS at bus 61 decreases the system loss to $0.72 \mathrm{MW}$. The total energies of PV and BESS during the day by incorporating one PV with BESS are presented in Figures 20 and 21. The system losses are decreased to $0.62 \mathrm{MW}$ and $0.60 \mathrm{MW}$ by integrating two and three PV with BES in RDS, respectively. Figures 22 and 23 illustrate the energies of PV and BESS during the day by installing two PV with BESS in RDS. Additionally, Figures 24 and 25 illustrate the energies of PV and BESS during the day by installing three PV with BESS in RDS. The total injection energies from PV to BESS and to the grid are presented in Table 5. Additionally, the charging and discharging energies of BESS are presented in Table 5 and Figure 25. 


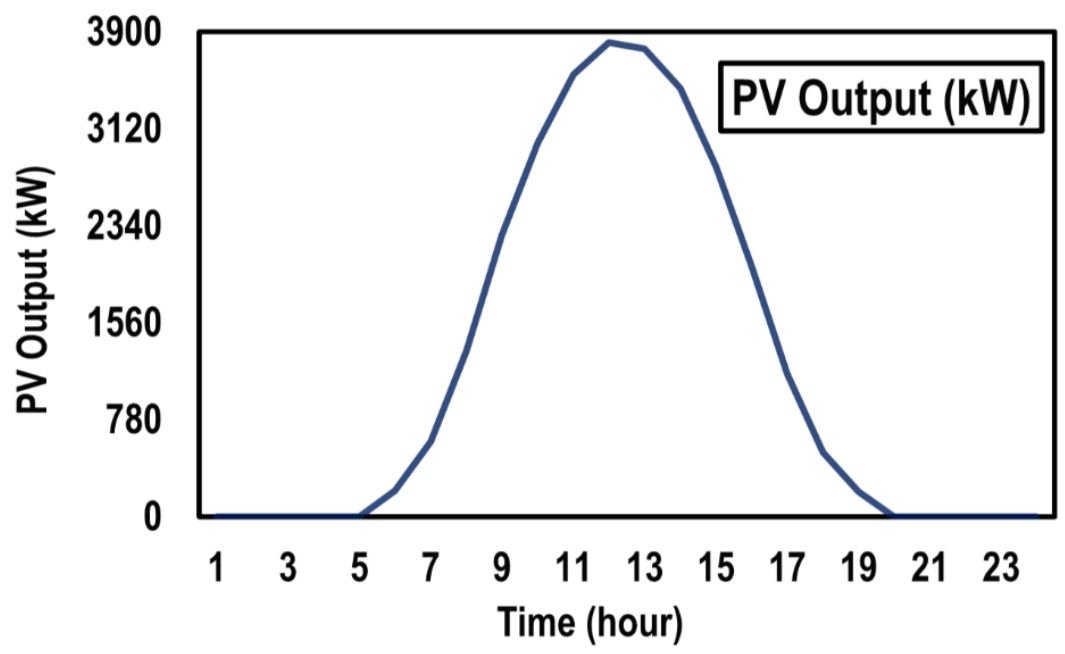

Figure 20. PV output during the day by installing one PV with BES in industrial system load.

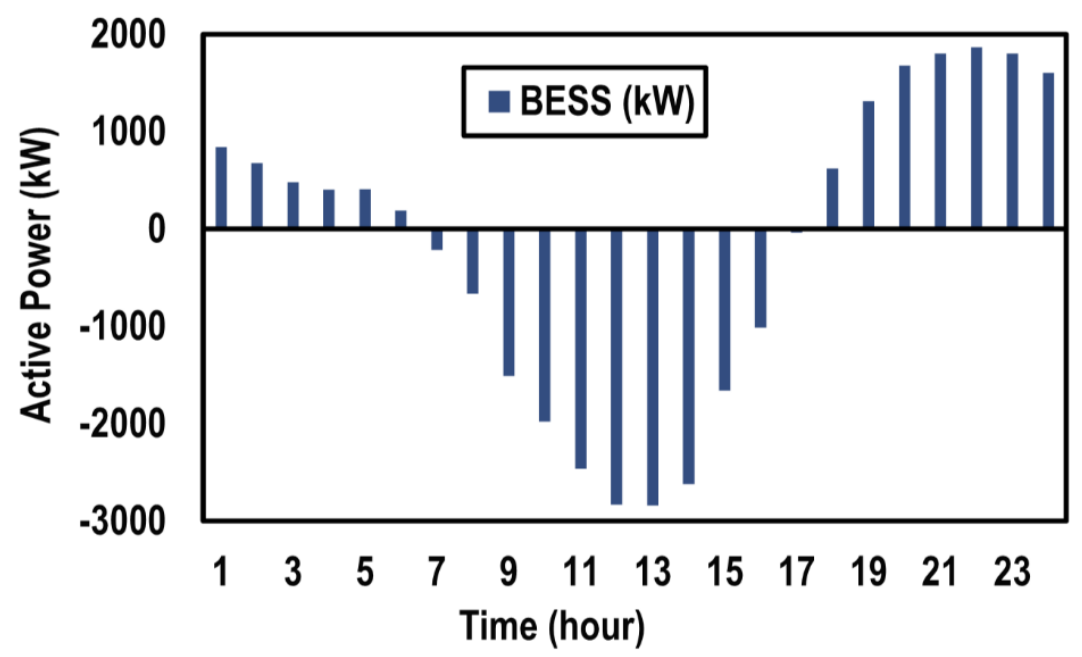

Figure 21. BES output during the day by installing one PV with BES in industrial system load.

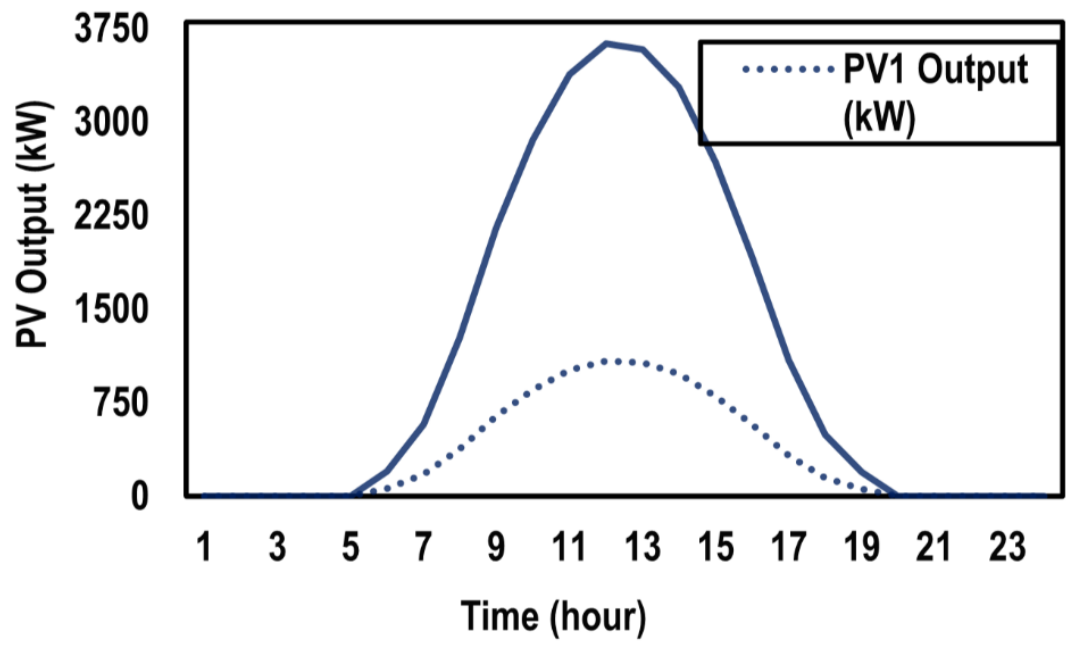

Figure 22. PV output during the day by installing two PV with BES in industrial system load. 


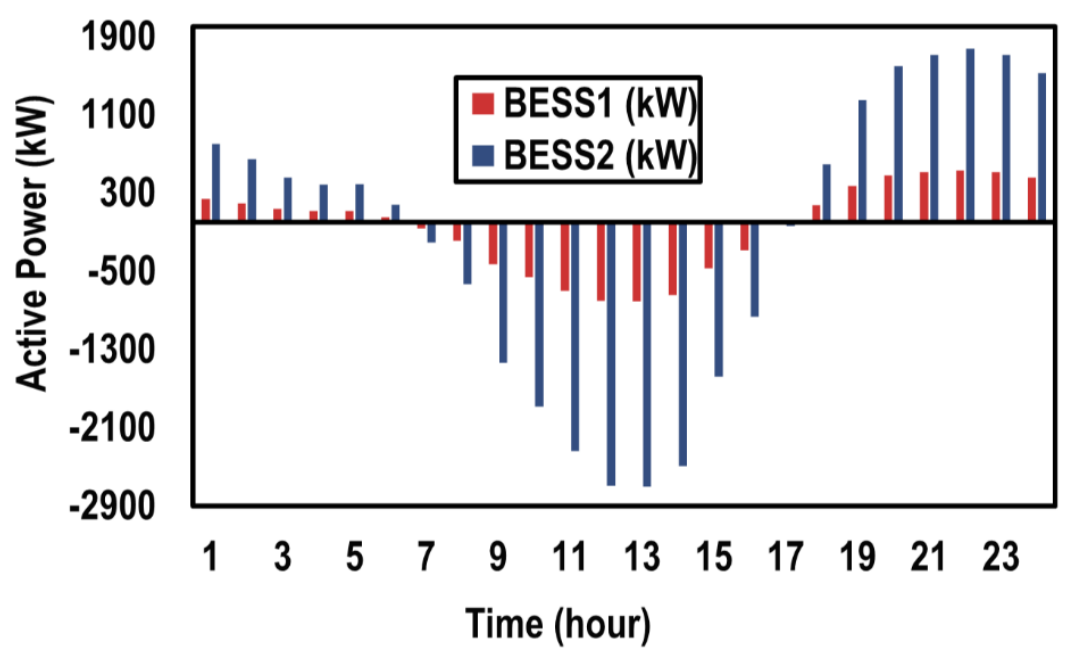

Figure 23. BES output during the day by installing two PV with BES in industrial system load.

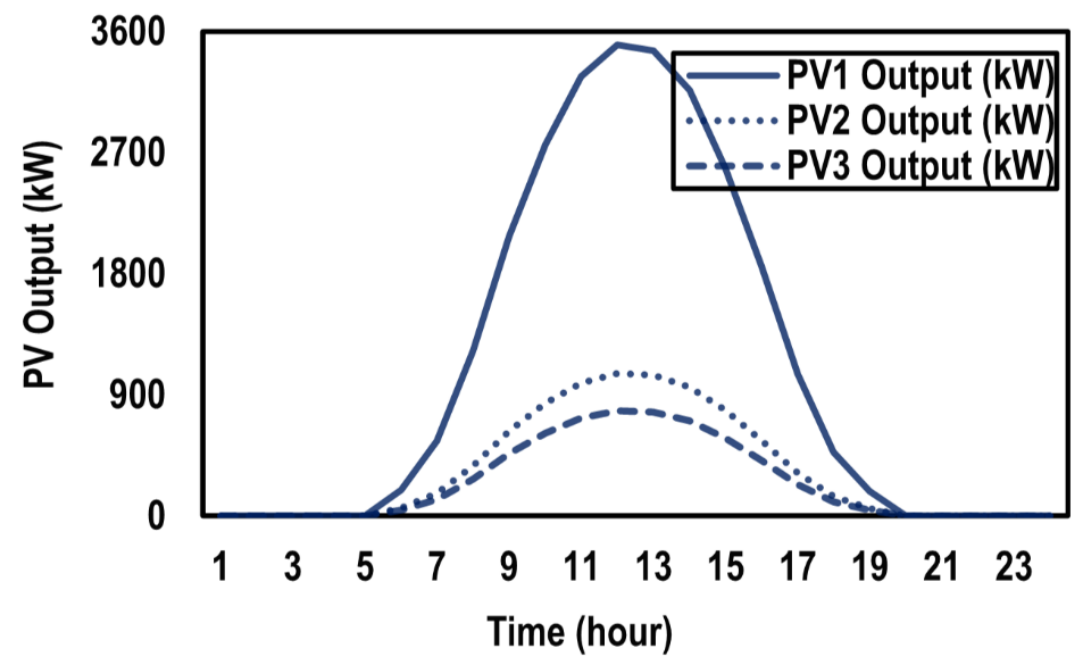

Figure 24. PV output during the day by installing two PV with BES in industrial system load.

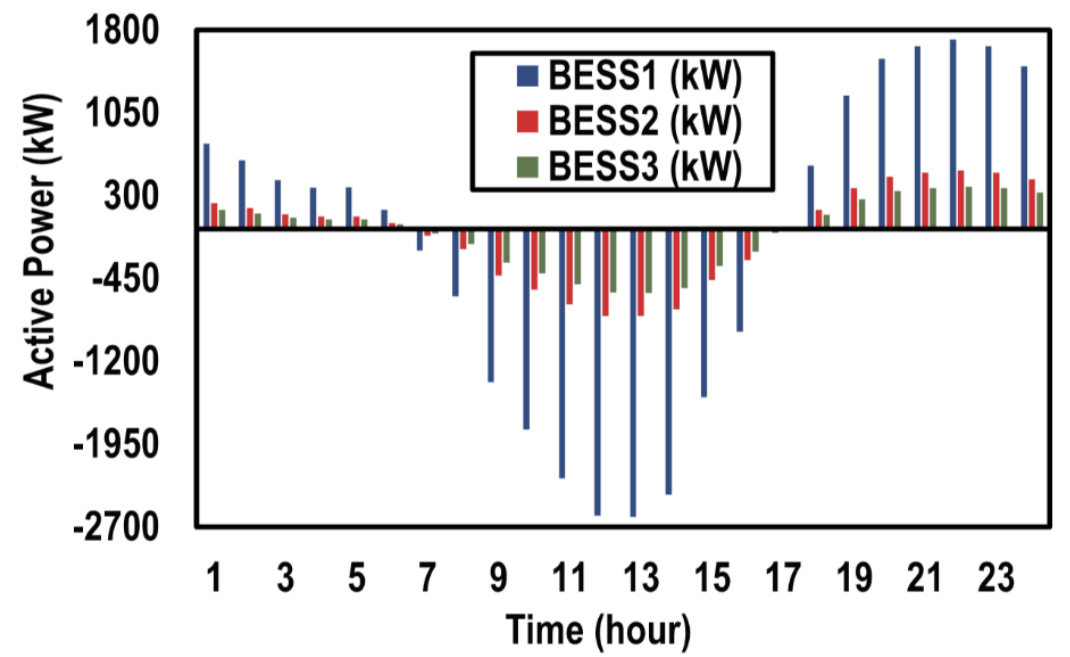

Figure 25. BES output during the day by installing three PV with BES in industrial system load. 
Table 5. The obtained results with and without installing PV with BES in industrial system loads.

\begin{tabular}{|c|c|c|c|c|c|c|c|c|}
\hline \multicolumn{3}{|c|}{ Item } & $\begin{array}{c}\text { Position } \\
(\text { Size }(\mathbf{k W}))\end{array}$ & $\begin{array}{l}\text { PV Energy } \\
\text { (kWh) }\end{array}$ & $\begin{array}{l}\text { EPV to grid } \\
(\mathbf{k W h})\end{array}$ & $\begin{array}{c}\text { Charging } \\
\text { Energy } \\
\text { (kWh) }\end{array}$ & $\begin{array}{c}\text { Discharging } \\
\text { Energy } \\
(\mathrm{kWh})\end{array}$ & $\begin{array}{l}P_{\text {loss }} \\
(\mathbf{k W})\end{array}$ \\
\hline \multirow{12}{*}{$\begin{array}{l}\text { Industrial } \\
\text { Load }\end{array}$} & \multicolumn{2}{|c|}{$\begin{array}{c}\text { Without } \\
\text { PV and BES }\end{array}$} & - & - & - & - & - & 1890.112 \\
\hline & \multirow{2}{*}{1} & PV & $61(3812.4)$ & 28,694 & 10,722 & - & - & \multirow{2}{*}{720.7217} \\
\hline & & BES & $61(2841.7)$ & - & - & 17,972 & 13,807 & \\
\hline & \multirow{3}{*}{2} & PV & 61 (3627.4) & $61(27,302)$ & $61(10,203)$ & - & - & 622.0804 \\
\hline & & \multirow{3}{*}{ BES } & $61(2703.8)$ & & & $61(17,099)$ & $61(13,137)$ & \multirow{8}{*}{603.1228} \\
\hline & & & $17(807.842)$ & & & $17(5108.2)$ & 17 (3924.5) & \\
\hline & \multirow{6}{*}{3} & & $61(3501.1)$ & $61(26,351)$ & $61(9848.4)$ & & & \\
\hline & & \multirow[t]{2}{*}{ PV } & 18 (780.37) & $18(5873.4)$ & $18(2203.4)$ & - & - & \\
\hline & & & $11(1060)$ & $11(7978)$ & $11(2964.7)$ & & & \\
\hline & & \multirow{3}{*}{ BES } & $61(2609.5)$ & & & $61(16,502)$ & $61(12,678)$ & \\
\hline & & & $18(580.93)$ & - & - & $17(3670.1)$ & 17 (2819.6) & \\
\hline & & & 11 (790.95) & & & $11(5013.3)$ & 11 (3851.6) & \\
\hline
\end{tabular}

\subsection{Commercial Load}

In this case, the overall reactive and real load demand during $24 \mathrm{~h}$ are $37.82 \mathrm{MVAr}$ and 53.35 MW, respectively. Without integrating BESS and PV in RDS, the overall reactive and real loss during $24 \mathrm{~h}$ are $0.99 \mathrm{MVAr}$ and $2.17 \mathrm{MW}$, respectively. The system power loss is reduced to $1.12 \mathrm{MW}$ with installing one PV alone at bus 61. The optimal placement and sizing of two PV alone at buses 61 and 17 decreases the system loss to 1.04 MW as shown in Table 6. Additionally, the optimal sizing of three PV alone at buses 61,18 , and 11 with total energy of 22.81 MWh decreases the system loss to $1.02 \mathrm{MW}$. From Figures 26 and 27, the total energies of one and two PV and three PV alone during the day are presented in Figure 26, Figure 27, and Figure 28, respectively.

Table 6. The obtained results with and without installing PV alone in commercial system loads.

\begin{tabular}{|c|c|c|c|c|c|}
\hline \multicolumn{2}{|c|}{ Item } & \multirow{2}{*}{$\begin{array}{c}\text { Position (Size (kW)) } \\
-\end{array}$} & \multirow{2}{*}{$\begin{array}{c}\text { PV Energy (kWh) } \\
-\end{array}$} & \multirow{2}{*}{$\begin{array}{c}\begin{array}{c}\text { Total PV Energy } \\
\text { (kWh) }\end{array} \\
-\end{array}$} & \multirow{2}{*}{$\begin{array}{r}\mathbf{P}_{\text {loss }}(\mathbf{k W}) \\
2173.851\end{array}$} \\
\hline \multirow{7}{*}{$\begin{array}{c}\text { Commercial } \\
\text { Load }\end{array}$} & Without PV & & & & \\
\hline & 1-PV & $61(2168.2)$ & $61(16,319)$ & 16,319 & 1124.5 \\
\hline & & $61(2063.1)$ & $61(15,527)$ & & \\
\hline & $2-P V$ & $17(611.6)$ & $17(4603)$ & 20,130 & 1038.2 \\
\hline & & 61 (1991.5) & $61(14,989)$ & & \\
\hline & 3-PV & $18(439.4)$ & $18(3306.8)$ & $22,809.30$ & 1021.7 \\
\hline & & $11(599.7)$ & $11(4513.5)$ & & \\
\hline
\end{tabular}

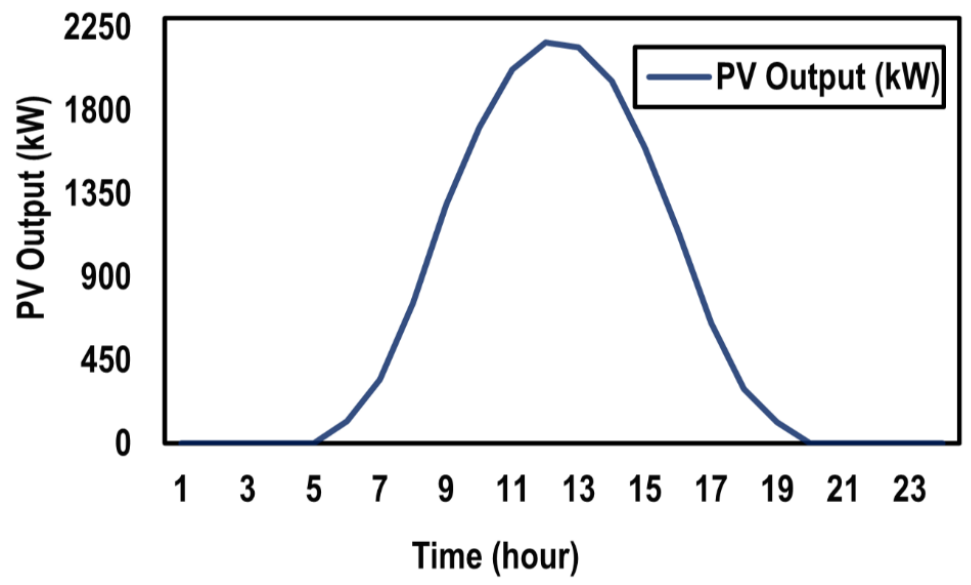

Figure 26. PV output during the day by installing one PV alone in commercial system load. 


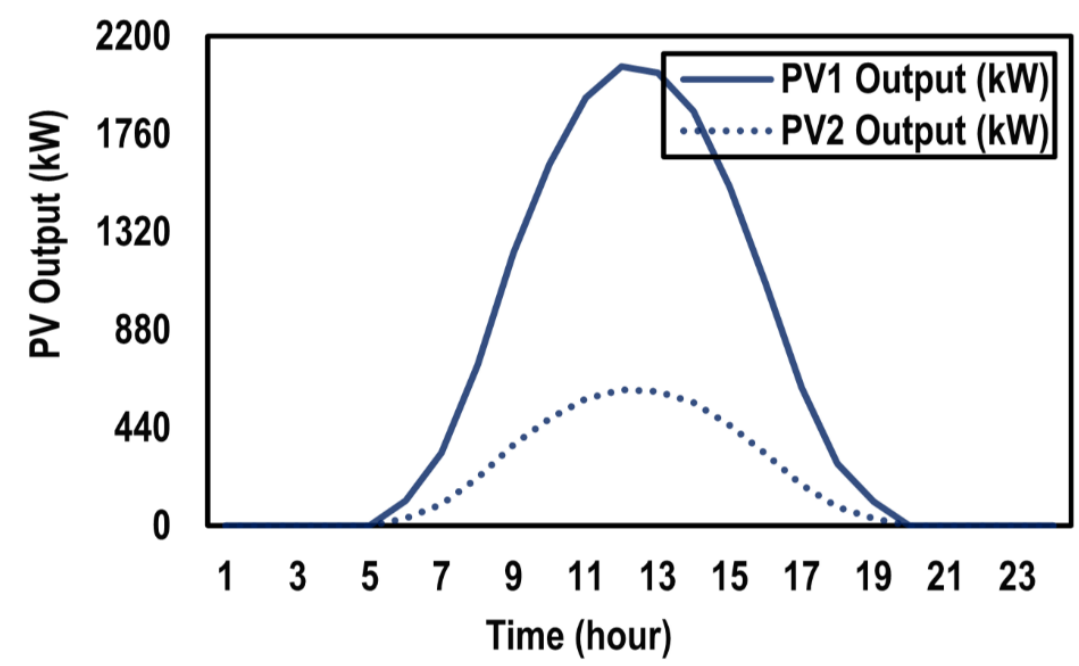

Figure 27. PV output during the day by installing two PV alone in commercial system load.

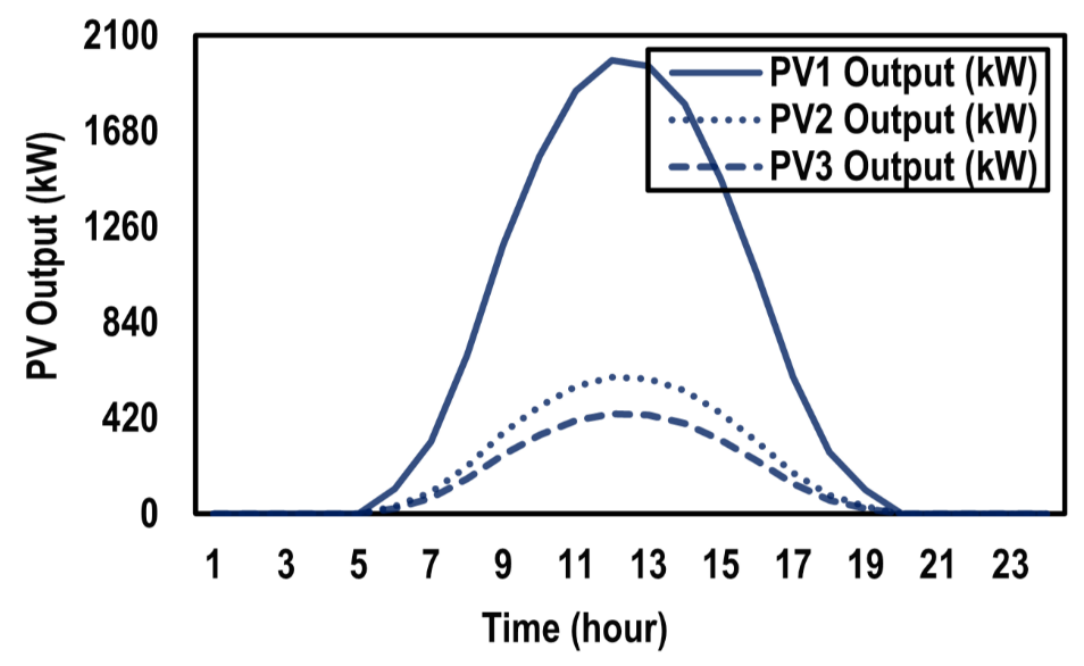

Figure 28. PV output during the day by installing three PV alone in commercial system load.

Installing one, two, and three PV with BES decreases the system losses to $0.83 \mathrm{MW}$, $0.71 \mathrm{MW}$, and 0.69 MW, respectively, as shown in Table 7. The total energy of PV and the charging and discharging energies of BES by integrating one PV with BES in RDS are illustrated in Figures 29 and 30. Figures 31 and 32 show the energies of two PV and the charging and discharging energies of BESS during the day, respectively. By incorporating three PV with BESS, the injection energies from PV to BESS and the grid during the day are shown in Figure 33, and the charging and discharging energies of BESS are shown in Figure 34. The results proved which the presented algorithm is an efficient to obtain the best global results when compared with modified HGSO algorithm and HGSO algorithm. This comparative study is illustrated in Table 8 . 
Table 7. The obtained results with and without installing PV with BES in commercial system loads.

\begin{tabular}{|c|c|c|c|c|c|c|c|c|}
\hline & Item & & $\begin{array}{c}\text { Position } \\
\text { (Size (kW)) }\end{array}$ & $\begin{array}{l}\text { PV Energy } \\
\text { (kWh) }\end{array}$ & $\begin{array}{l}\mathrm{E}_{\mathrm{PV} \text { to grid }} \\
(\mathrm{kWh})\end{array}$ & $\begin{array}{l}\text { Charging } \\
\text { Energy } \\
\text { (kWh) }\end{array}$ & $\begin{array}{l}\text { Discharging } \\
\text { Energy } \\
\text { (kWh) }\end{array}$ & $\begin{array}{l}P_{\text {loss }} \\
(\mathbf{k W})\end{array}$ \\
\hline \multirow{12}{*}{$\begin{array}{l}\text { Commercial } \\
\text { Load }\end{array}$} & \multicolumn{2}{|c|}{$\begin{array}{c}\text { Without } \\
\text { PV and BES }\end{array}$} & - & - & - & - & - & 2173.851 \\
\hline & \multirow[b]{2}{*}{1} & $\mathrm{PV}$ & $61(3832.2)$ & 28,843 & 17,155 & - & - & 825.1585 \\
\hline & & BES & $61(2064.9)$ & - & - & 11,688 & 8936.1 & \\
\hline & \multirow{3}{*}{2} & PV & $\begin{array}{l}61(3644.3) \\
17(1089.2)\end{array}$ & $\begin{array}{l}61(27,429) \\
17(8197.6)\end{array}$ & $\begin{array}{l}61(16,253) \\
17(4853.2)\end{array}$ & - & - & 709.9147 \\
\hline & & \multirow{3}{*}{ BES } & 61 (1945.8) & & & $61(11,175)$ & $61(8544.5)$ & \\
\hline & & & $17(582.223)$ & - & - & $17(3344.4)$ & $17(2557.1)$ & \\
\hline & \multirow{6}{*}{3} & & $61(3517.3)$ & 61 (26473) & $61(15685)$ & & & \\
\hline & & \multirow[t]{2}{*}{ PV } & $18(783.5)$ & 18 (5897.1) & $18(3483.5)$ & - & - & 688.1289 \\
\hline & & & 11 (1065.6) & $11(8020.3)$ & $11(4777.6)$ & & & \\
\hline & & \multirow{3}{*}{ BES } & 61 (1878.5) & & & $61(10788)$ & $61(8248.5)$ & \\
\hline & & & 18 (420.22) & - & - & 18 (2413.6) & 18 (1845.4) & \\
\hline & & & $11(564.685)$ & & & $11(3242.7)$ & $11(2479.4)$ & \\
\hline
\end{tabular}

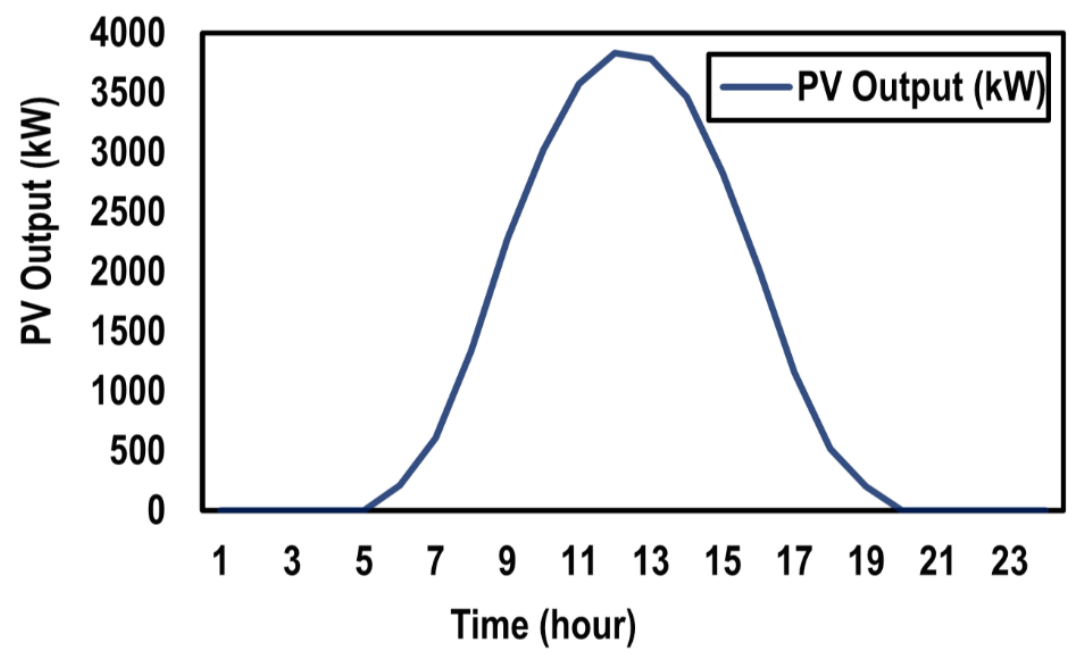

Figure 29. PV output during the day by installing one PV with BES in commercial system load.

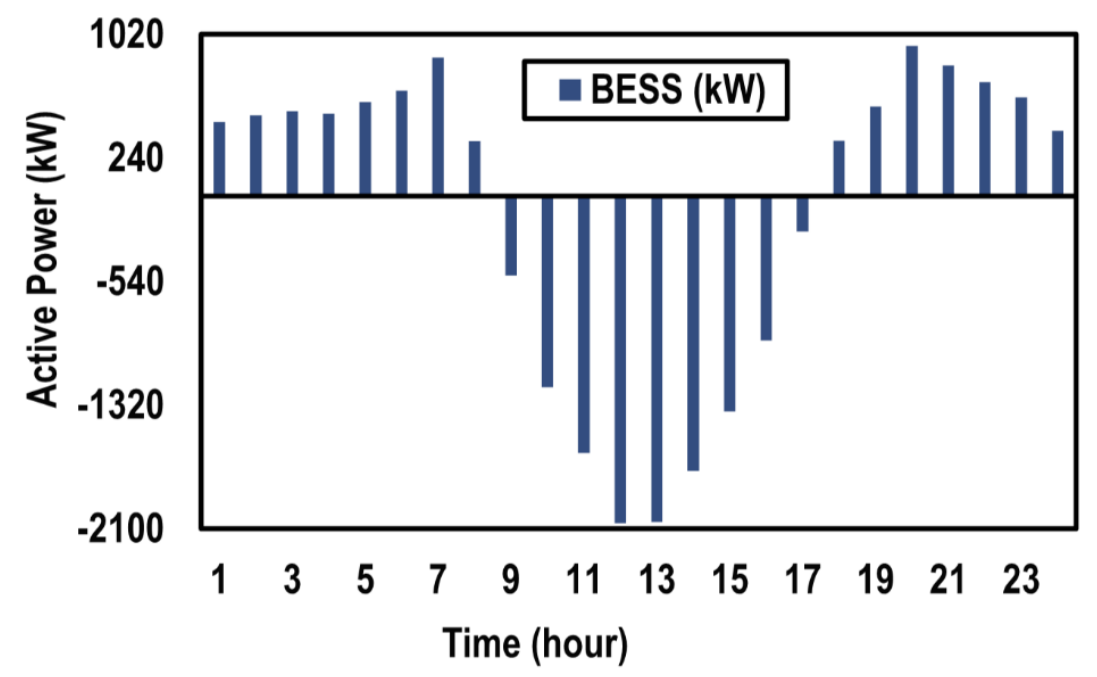

Figure 30. BES output during the day by installing one PV with BES in commercial system load. 


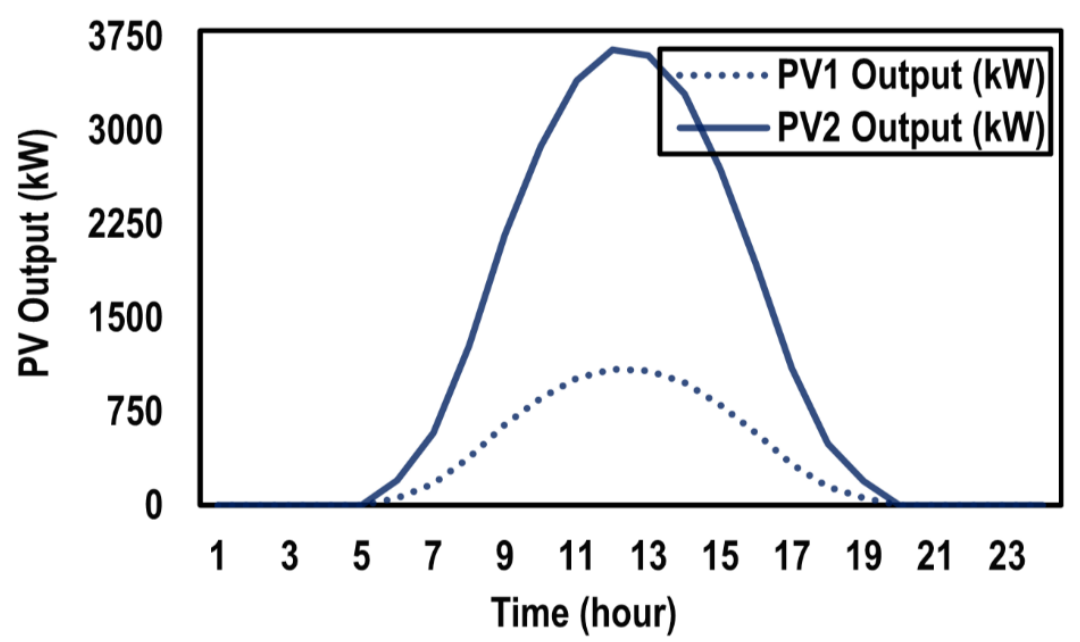

Figure 31. PV output during the day by installing two PV with BES in commercial system load.

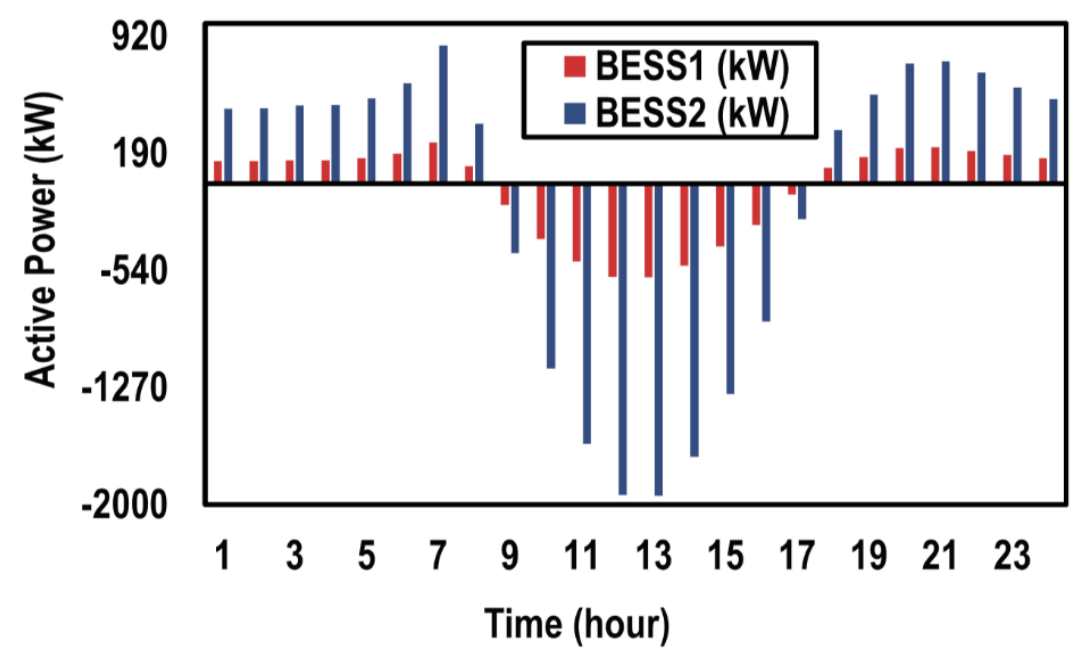

Figure 32. BES output during the day by installing two PV with BES in commercial system load.

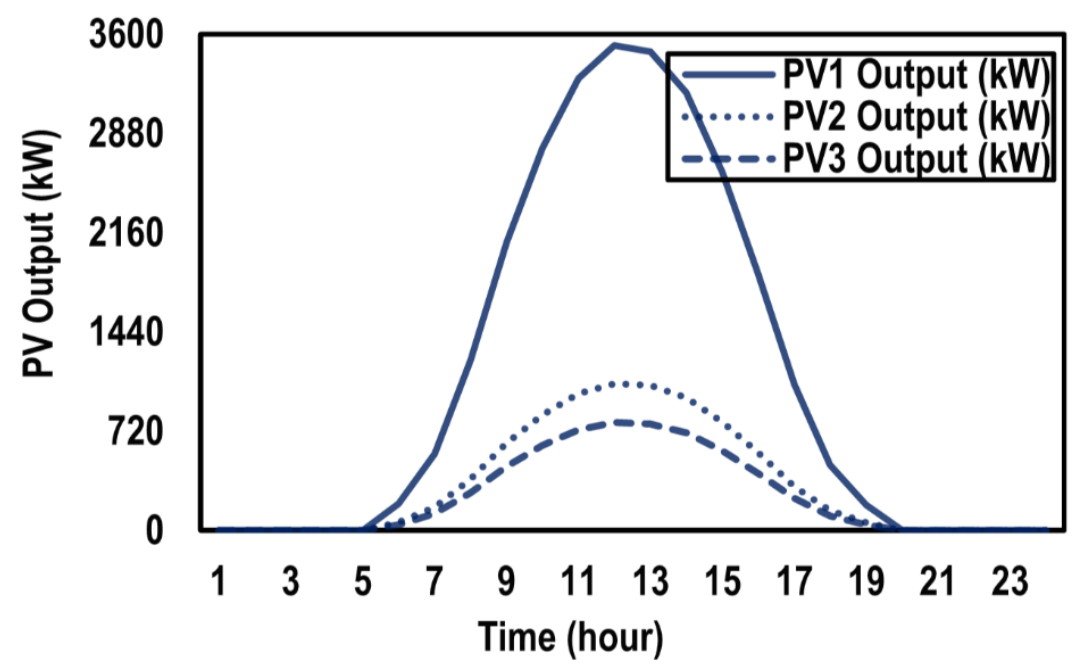

Figure 33. PV output during the day by installing three PV with BES in commercial system load. 


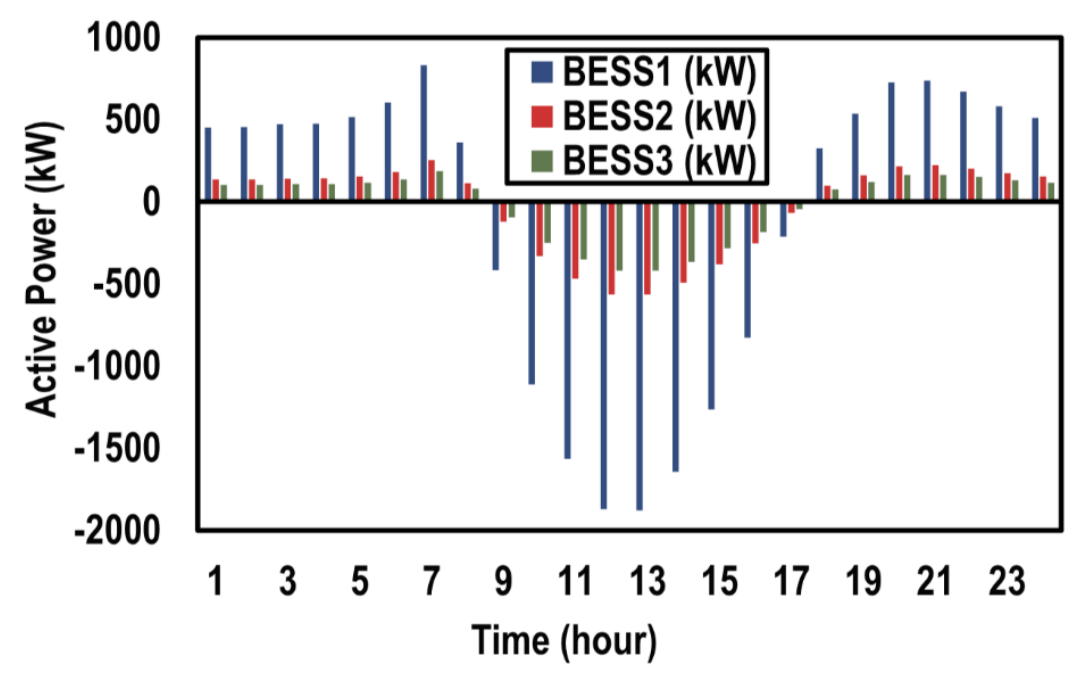

Figure 34. BES output during the day by installing three PV with BES in commercial system load.

Table 8. Comparison results between AOA, Modified HGSO, and HGSO algorithms in commercial system load.

\begin{tabular}{cccc}
\hline Item & AOA & Modified HGSO [36] & HGSO [36] \\
\hline$P_{\text {loss }}(\mathrm{kW})$ Without PV and & 2173.851 & 2173.851 & 2173.851 \\
BES & $61(3517.3)$ & $61(3517.488)$ & $61(3187.526)$ \\
& $18(783.5)$ & $18(784.1074)$ & $18(860.6001)$ \\
Location (PV size $(\mathrm{kW}))$ & $11(1065.6)$ & $11(1064.323)$ & $11(934.0223)$ \\
& $61(1878.5)$ & $61(1878.5)$ & $61(1911.138)$ \\
Location (BES size $(\mathrm{kW}))$ & $18(420.22)$ & $18(420.843)$ & $18(486.4727)$ \\
$\mathrm{P}_{\text {loss }}(\mathrm{kW})$ & $11(564.685)$ & 688.129 & $11(595.803)$ \\
\hline
\end{tabular}

\section{Conclusions}

In this paper, an application for a recent optimization algorithm called the Archimedes optimization algorithm (AOA) has been proposed for reducing energy losses and to capture the size of incorporating battery energy storage system (BESS) and photovoltaic (PV) energy system in RDS. In this paper, all non-dispatchable PV energy systems have been transformed into a dispatchable energy resource with BESS integration with PV. AOA has been evolved for sizing several PV and BESS considering the changing demand over time and the probability generation. The proposed algorithm has been applied on the IEEE 69-bus distribution network with various daily demand configurations such as residential, industrial, and commercial loads demand. The obtained results demonstrate that the model can boost high penetration of the PV energy system accompanied with effective usage of BESS energy resources, which shows the strength of the presented algorithm for evaluating the best sizing of numerous PV and BESS with a significant reduction in energy losses. In addition, the AOA gives better results compared with other well-known optimization algorithms.

Author Contributions: Conceptualization, H.A.-M. and S.K.; data curation, M.T.-V. and E.E.E.; formal analysis, M.M.H.; methodology, M.T.-V. and E.E.E.; software, H.A.-M. and S.K.; supervision, M.M.H. and E.E.E.; validation, H.A.-M. and S.K.; visualization, M.T.-V.; writing-original draft, H.A.-M. and S.K.; writing-review and editing, M.T.-V., M.M.H. and E.E.E. All authors together organized and refined the manuscript in the present form. All authors have read and agreed to the published version of the manuscript.

Funding: This work was supported by Taif University Researchers Supporting Project number (TURSP-2020/86): Taif University, Taif, Saudi Arabia. 
Institutional Review Board Statement: Not applicable.

Informed Consent Statement: Not applicable.

Data Availability Statement: Not applicable.

Conflicts of Interest: The authors declare no conflict of interest.

\section{References}

1. Omran, W.A.; Kazerani, M.; Salama, M.M.A. Investigation of methods for reduction of power fluctuations generated from large grid-connected photovoltaic systems. IEEE Trans. Energy Convers. 2011, 26, 318-327. [CrossRef]

2. Dincer, F. The analysis on photovoltaic electricity generation status, potential and policies of the leading countries in solar energy. Renew. Sustain. Energy Rev. 2011, 15, 713-720. [CrossRef]

3. Liu, F.; Li, R.; Li, Y.; Yan, R.; Saha, T. Takagi-Sugeno fuzzy model-based approach considering multiple weather factors for the photovoltaic power short-term forecasting. IET Renew. Power Gener. 2017, 11, 1281-1287. [CrossRef]

4. Rizwan, M.; Mujtaba, G.; Memon, S.A.; Lee, K.; Rashid, N. Exploring the potential of microalgae for new biotechnology applications and beyond: A review. Renew. Sustain. Energy Rev. 2018, 92, 394-404. [CrossRef]

5. Yang, M.; Huang, X. Ultra-short-term prediction of photovoltaic power based on periodic extraction of PV energy and LSH algorithm. IEEE Access 2018, 6, 51200-51205. [CrossRef]

6. Dawoud, S.M.; Lin, X.; Okba, M.I. Hybrid renewable microgrid optimization techniques: A review. Renew. Sustain. Energy Rev. 2018, 82, 2039-2052. [CrossRef]

7. Zia, M.F.; Elbouchikhi, E.; Benbouzid, M. Microgrids energy management systems: A critical review on methods, solutions, and prospects. Appl. Energy 2018, 222, 1033-1055. [CrossRef]

8. Siddaiah, R.; Saini, R. A review on planning, configurations, modeling and optimization techniques of hybrid renewable energy systems for off grid applications. Renew. Sustain. Energy Rev. 2016, 58, 376-396. [CrossRef]

9. Niknam, T.; Taheri, S.I.; Aghaei, J.; Tabatabaei, S.; Nayeripour, M. A modified honey bee mating optimization algorithm for multiobjective placement of renewable energy resources. Appl. Energy 2011, 88, 4817-4830. [CrossRef]

10. Taher, N. A new HBMO algorithm for multiobjective daily Volt/Var control in distribution systems considering distributed generators. Appl. Energy 2011, 88, 778-788.

11. Bakos, G.C. Distributed power generation: A case study of small scale PV power plant in Greece. Appl. Energy 2009, 86, 1757-1766. [CrossRef]

12. Wang, C.; Nehrir, M.H. Analytical approaches for optimal placement of distributed generation sources in power systems. IEEE Trans. Power Syst. 2004, 19, 2068-2076. [CrossRef]

13. Acharya, N.; Mahat, P.; Mithulananthan, N. An analytical approach for DG allocation in primary distribution network. Int. J. Electr. Power Energy Syst. 2006, 28, 669-678. [CrossRef]

14. Kasturi, K.; Nayak, M.R. Optimal Planning of Charging Station for EVs with PV-BES Unit in Distribution System Using WOA. In Proceedings of the 2017 IEEE 2nd International Conference on Man and Machine Interfacing (MAMI), Bhubaneswar, India, 21-23 December 2017; pp. 1-6.

15. Dixit, M.; Kundu, P.; Jariwala, H.R. Optimal placement of photo-voltaic array and electric vehicles in distribution system under load uncertainty. In Proceedings of the 2017 IEEE Power \& Energy Society General Meeting, Chicago, IL, USA, 16-20 July 2017; pp. 1-5.

16. Yeh, H.G.; Gayme, D.F.; Low, S.H. Adaptive VAR control for distribution circuits with photovoltaic generators. IEEE Trans. Power Syst. 2012, 27, 1656-1663. [CrossRef]

17. Turitsyn, K.; Sulc, P.; Backhaus, S.; Chertkov, M. Options for control of reactive power by distributed photovoltaic generators. Proc. IEEE 2011, 99, 1063-1073. [CrossRef]

18. Sugihara, H.; Yokoyama, K.; Saeki, O.; Tsuji, K.; Funaki, T. Economic and efficient voltage management using customer-owned energy storage systems in a distribution network with high penetration of photovoltaic systems. IEEE Trans. Power Syst. 2013, 28, 102-111. [CrossRef]

19. Teng, J.H.; Luan, S.W.; Lee, D.J.; Huang, Y.Q. Optimal charging/discharging scheduling of battery storage systems for distribution systems interconnected with sizeable PV generation systems. IEEE Trans. Power Syst. 2013, 28, 1425-1433. [CrossRef]

20. Teleke, S.; Baran, M.E.; Bhattacharya, S.; Huang, A.Q. Rule-based control of battery energy storage for dispatching intermittent renewable sources. IEEE Trans. Sustain. Energy 2010, 1, 117-124. [CrossRef]

21. Hill, C.A.; Such, M.C.; Dongmei, C.; Gonzalez, J.; Grady, W.M. Battery energy storage for enabling integration of distributed solar power generation. IEEE Trans. Smart Grid 2012, 3, 850-857. [CrossRef]

22. Borowy, B.S.; Salameh, Z.M. Methodology for optimally sizing the combination of a battery bank and PV array in a wind/PV hybrid system. IEEE Trans. Energy Convers. 1996, 11, 367-375. [CrossRef]

23. Ekren, O.; Ekren, B.Y. Size optimization of a PV/wind hybrid energy conversion system with battery storage using response surface methodology. Appl. Energy 2008, 85, 1086-1101. [CrossRef]

24. Avril, S.; Arnaud, G.; Florentin, A.; Vinard, M. Multi-objective optimization of batteries and hydrogen storage technologies for remote photovoltaic systems. Energy 2010, 35, 5300-5308. [CrossRef] 
25. Castillo-Cagigal, M.; Gutiérrez, A.; Monasterio-Huelin, F.; Caamaño-Martín, E.; Masa, D.; Jiménez-Leube, J. A semi-distributed electric demand-side management system with PV generation for self-consumption enhancement. Energy Convers. Manag. 2011, 52, 2659-2666. [CrossRef]

26. Wei-Fu, S.; Shyh-Jier, H.; Chin, E.L. Economic analysis for demand-side hybrid photovoltaic and battery energy storage system. IEEE Trans. Ind. Appl. 2001, 37, 171-177. [CrossRef]

27. Nottrott, A.; Kleissl, J.; Washom, B. Energy dispatch schedule optimization and cost benefit analysis for grid-connected, photovoltaic-battery storage systems. Renew. Energy 2013, 55, 230-240. [CrossRef]

28. Yu, R.; Kleissl, J.; Martinez, S. Storage size determination for grid-connected photovoltaic systems. IEEE Trans. Sustain. Energy 2013, 4, 68-81.

29. Tant, J.; Geth, F.; Six, D.; Tant, P.; Driesen, J. Multiobjective battery storage to improve PV integration in residential distribution grids. IEEE Sustain. Energy 2013, 4, 182-191. [CrossRef]

30. Alam, M.J.E.; Muttaqi, K.M.; Sutanto, D. Mitigation of rooftop solar PV impacts and evening peak support by managing available capacity of distributed energy storage systems. IEEE Trans. Power Syst. 2013, 28, 3874-3884. [CrossRef]

31. Daud, M.Z.; Mohamed, A.; Hannan, M.A. An improved control method of battery energy storage system for hourly dispatch of photovoltaic power sources. Energy Convers. Manag. 2013, 73, 256-270. [CrossRef]

32. Eminoglu, U.; Hocaoglu, M.H. Distribution systems forward/backward sweep-based power flow algorithms: A review and comparison study. Electr. Power Compon. Syst. 2008, 37, 91-110. [CrossRef]

33. Abdel-mawgoud, H.; Kamel, S.; Ebeed, M.; Youssef, A.-R. Optimal allocation of renewable dg sources in distribution networks considering load growth. In Proceedings of the 2017 Nineteenth International Middle East Power Systems Conference (MEPCON), Cairo, Egypt, 19-21 December 2017; pp. 1236-1241.

34. El-Fergany, A. Optimal allocation of multi-type distributed generators using backtracking search optimization algorithm. Int. J. Electr. Power Energy Syst. 2015, 64, 1197-1205. [CrossRef]

35. Ali, E.; Elazim, S.A.; Abdelaziz, A. Ant lion optimization algorithm for renewable distributed generations. Energy 2016, 116, 445-458. [CrossRef]

36. Abdel-Mawgoud, H.; Kamel, S.; Khasanov, M.; Khurshaid, T. A strategy for PV and BESS allocation considering uncertainty based on a modified Henry gas solubility optimizer. Electr. Power Syst. Res. 2021, 191, 106886. [CrossRef]

37. Aman, M.; Jasmon, G.; Bakar, A.; Mokhlis, H. A new approach for optimum simultaneous multi-DG distributed generation Units placement and sizing based on maximization of system loadability using HPSO (hybrid particle swarm optimization) algorithm. Energy 2014, 66, 202-215. [CrossRef]

38. Lopez, E.; Opazo, H.; Garcia, L.; Bastard, P. Online reconfiguration considering variability demand: Applications to real networks. IEEE Trans. Power Syst. 2004, 19, 549-553. [CrossRef]

39. Hung, D.Q.; Mithulananthan, N.; Lee, K.Y. Determining PV penetration for distribution systems with time-varying load models. IEEE Trans. Power Syst. 2014, 29, 3048-3057. [CrossRef]

40. Price, W.; Casper, S.G.; Nwankpa, C.O.; Bradish, R.W.; Chiang, H.-D.; Concordia, C.; Staron, J.V.; Taylor, C.W.; Vaahedi, E. Bibliography on load models for power flow and dynamic performance simulation. IEEE Power Eng. Rev. 1995, 15, 70.

41. Salameh, Z.M.; Borowy, B.S.; Amin, A.R. Photovoltaic module-site matching based on the capacity factors. IEEE Trans. Energy Convers. 1995, 10, 326-332. [CrossRef]

42. Hung, D.Q.; Mithulananthan, N.; Bansal, R. Integration of PV and BES units in commercial distribution systems considering energy loss and voltage stability. Appl. Energy 2014, 113, 1162-1170. [CrossRef]

43. Gabash, A.; Pu, L. Active-reactive optimal power flow in distribution networks with embedded generation and battery storage. IEEE Trans. Power Syst. 2012, 27, 2026-2035. [CrossRef]

44. Chen, S.; Gooi, H.B.; Wang, M. Sizing of energy storage for microgrids. IEEE Trans. Smart Grid 2011, 3, 142-151. [CrossRef]

45. Hashim, F.A.; Hussain, K.; Houssein, E.H.; Mabrouk, M.S.; Al-Atabany, W. Archimedes optimization algorithm: A new metaheuristic algorithm for solving optimization problems. Appl. Intell. 2020, 51, 1531-1551. [CrossRef]

46. Rorres, C. Completing book ii of archimedes's on floating bodies. Math. Intell. 2004, 26, 32-42. [CrossRef]

47. Savier, J.; Das, D. Impact of network reconfiguration on loss allocation of radial distribution systems. IEEE Trans. Power Deliv. 2007, 22, 2473-2480. [CrossRef] 